\title{
EXPERIMENTAL STUDIES OF SUPERCAVITATING FLOW ABOUT SIMPLE TWO-DIMENSIONAL BODIES IN A JET
}

\author{
Submitted by \\ LORENZ G. STRAUB \\ Director \\ Prepared by \\ EDWARD SILBERMAN
}

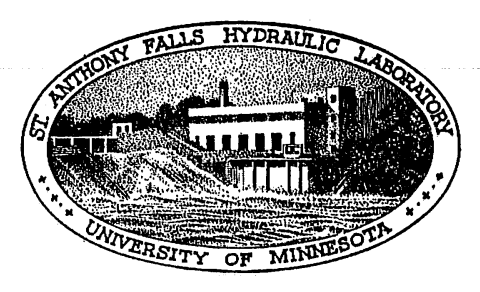

April 1958

Prepared for

OFFICE OF NAVAL RESEARCH

Department of the Navy

Washington, D.C.

Office of Naval Research Contract Nonr 710(24) 
Reproduction in whole or in part is permitted for any purpose of the United States Govermment 


$$
\underline{A} \underline{B} \underline{S} \underline{T} \underline{R} \underline{A} \underline{C} \underline{T}
$$

A two-dimensional free-jet water tunnel is described briefly. Results of experimental measurements on a two-dimensional cup, symetrical

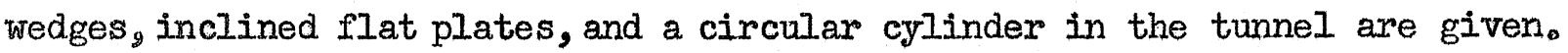

Measured force coefficients at zero cavitation number are in good agreement with theory. Shapes of the cavities were computed for one of the wedges and for one of the plates at zero cavitation number; the observed shapès are also in good agreement with the theory.

For nonzero cavitation numbers, theoretical results for force coefficients were available for comparison in only two cases. For one of these, the cup, agreement between theory and experiment was good up to a cavitation number of about 0.5. For the other, a symmetrical wedge, experimental results were compared with a linear theory with good agreement for cavitation numbers between about 0.1 and 0.3 . In the case of the wedge, measured cavity lengths were somewhat shorter than predicted by the linear theory. All other comparisonswith theory at nonzero cavitation number had to be made with the theory as developed for infinite fluid. The experimental force coefficients were less than predicted by infinitemfluid theory, but tended to approach the theoretical values as the cavitation number increased. A similar tendency marked the comparison between the experimental data and data taken by others in closed tunnels. 
$\underline{0} \underline{\mathbb{N}} \underline{\mathrm{E}} \underline{\mathrm{T}} \mathrm{S}$

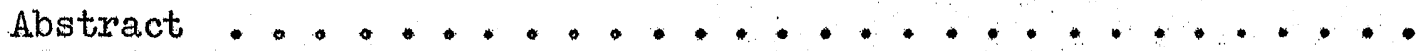

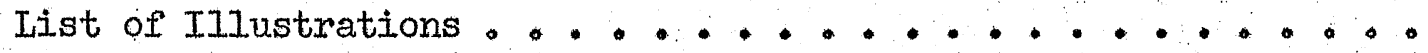

I. INPRODUCTION $\ldots \ldots \ldots \ldots \ldots$

II。 THE FREE-JET TUNNEL . . . . . . . . . . . . . . 2

III. EXPERIMENTAI RESULTS . . . . . . . . . . . 4

IV. EFEECT OF GRAVITY . . . . . . . . . . . 7

V. COMPARISON WITH THEORY AND WITH MEASUREMENTS BY OTHERS • . 8

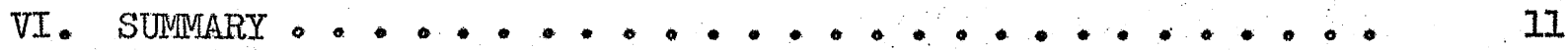

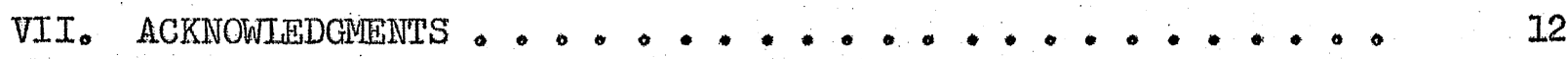

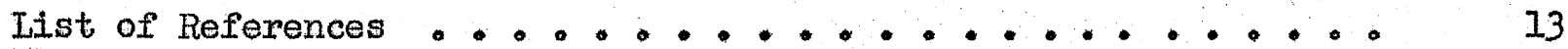

Figures 1 through $9 \ldots \ldots 17$

Appendix A - Drag Corrections . . . . . . . . . . . . . 29

Appendix B - Free-Streamline Solution for an Inclined Flat Plate

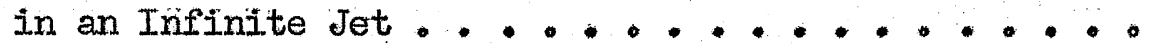




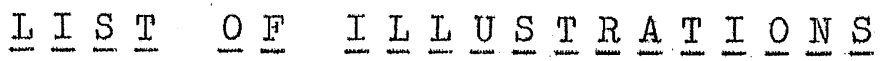

Figure

Page

1 General Scheme of Water Tunnel . . . . . . . . 17

2 Views of Two-Dimensional Test Section . . . . . . 18

3 Drag Coefficient for Two-Dimensional Cup . . . . . . 19

4 Drag Coefficients for Symmetrical Wedges . . . . . . . 20

5 Lift and Drag Coefficients for Inclined Flat Plates . . * 21

6 Drag Coefficient for Circular Cylinder . . . . . . . . 22

7 Typical Cavity Length Measurements . . . . . . . . 23

8 Typical Cavities . . . . . . . . . . . . . . . 24

9 Effect of Gravity on Flat-Plate Lift Coefficient . . . . 25

B-I Conformal Mapping Planes . . . . . . . . . . 36

B-2 Force Coefficients for Flat Plates in Free Jet at Zero

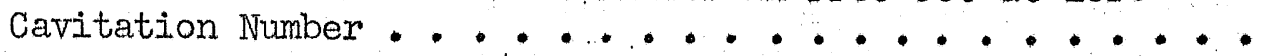


the two-dimensional plates with an 0.01-in. annular gap. Load is transferred from a test body to the dynamometers through circular hubs on the disks which fit snugly into holes in the dynamometer. Set screws keep the hubs from turning or moving endwise, once angle of attack has been established. Application of load produces a small displacement in part of the dynamometer and in the covering disks. The annular gap thus becomes asymmetrical. There is some leakage through the annular gap, and this leakage sometimes interferes with cavity, observation; the leakage does not appear to influence force measurements.

Water velocity is determined by measuring the pressure drop in the nozzle leading to the jet. The pressure drop was previously calibrated against velocity by weighing the discharge up to velocities of about $30 \mathrm{fps}$; the calibration curve was linear up to this velocity and the straight line was extended to the highest velocities. The calibration curve was verified by measurements in the jet with a Pitot-static tube up to the highest velocities. The Pitot-static-tube measurements also demonstrated that the velocity between the side plates at the test-body location, at $L O$ fps mean velocity, was uniform within $I$ per cent; any boundary layer was confined to a region $1 / 4$ in. thick near each wall which could not be reached by the Pitot-static tube. This uniform velocity profile makes it possible, for computational purposes, to consider the flow to be that of an ideal, infinite, two-dimensional jet rather, than a jet from a nozzle.

The calibrated velocity occurs at the end of the nozzle. The actual velocity head at the test body is composed of the velocity head at the nozzle exit plus the vertical distance from nozzle exit to center of test body -7 inches in this tunnel. That this is the case was verified by measurements with a total-head tube with no body in the tunnel.

\section{EXPERIMENTAL RESULTS}

Some experimental force coefficients are shown in Figs. 3 through 6. Cavity lengths, measured from photographs, are given in Fig. 7. Typical photographs are shown in Fig. 8. The shapes investigated were a two-dimensional cup (Fig.3), two symmetrical wedges (Fig. 4), flat plates at four angles of attack (Fig. 5), and a circular cylinder (Fig. 6). 
In presenting the data, the following parameters are used:

Cavitation Number:

or:

Lift Coefficient:

Drag Coefficient:

Reynolds Number:

$$
\begin{gathered}
\sigma=\frac{p_{0}-p_{k}}{q} \\
\sigma_{\nabla}=\frac{p_{0}-p_{V}}{q}
\end{gathered}
$$
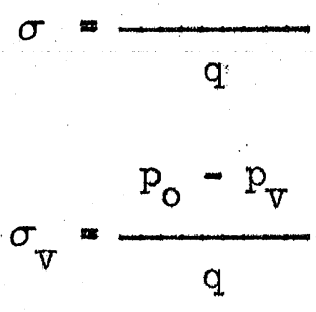

where $p_{0}$ is the measured pressure in the chamber surrounding the jet,

$\mathrm{p}_{\mathrm{k}}$ is the measured cavity pressure,

$\mathrm{p}_{\mathrm{V} \text {... }}$ is the vapor pressure of water at the operating temperature;

$q=\rho U_{0}^{2} / 2$ is the reference dynamic pressure,

$U_{0}$ is the velocity which would exist in the undisturbed jet at the position of the center of the test body,

$I$ is the lift or net force on the body normal to $U_{0}$,

$D$ is the drag or net force on the body parallel to $U_{0}$,

$c$ is the chord length or other characteristic dimension of the body,

$\ell$ is the span ( 5 inches in this tunnel),

$\rho$. is the density of the water, and

$\nu$ is the coefficient of kinematic viscosity of the water.

In the case of one of the wedges (Fig. Lb) and for the circular cylinder (Figs. $6 \mathrm{~b}$ and $6 \mathrm{c}$ ) the experiments were carried into the noncavitating range. In these two cases the cavitation number is defined by Eq. (Ia) because it was impossible to measure cavity pressure directly. All other experiments were limited to the very small cavitation numbers associated with supercavitating flows; cavity pressure was measured directly and cavitation number is 
defined by Eq. (1). Almost all the data were obtained in a range of velocities $U_{0}$ from about 38 to $45 \mathrm{fps}$. Some data were obtained at velocities as low as $20 \mathrm{fps}$; these data are appropriately indicated where they occur.

The lift I was taken directly from measured data for use in $\mathrm{Eq}$. (2). The drag coefficient in Eq. (3) was corrected by subtracting the cal, culated skin-friction drag coefficient for the end disks and the calculated skin-friction drag coefficient for the test body before plotting the data. The corrections are described in Appendix A. Therefore, the plotted drag coefficients relate to form or cavitation drag of the test bodies.

For the flat plates at small angles of attack, it was found that the drag coefficient, especially, was very sensitive to the sharpness of the leading edge. These edges were kept honed, and the tunnel was stopped and the , edges were cleaned after each measurement was obtained. (Bits of grass from the river water accumulated on the leading edges。) Nevertheless, the drag data were difficult to reproduce as may be seen in Figs。 $5 \mathrm{a}$ and $5 \mathrm{c}$.

Three different classes of cavities were generated. Naturally occurring, closed cavities are indicated by circles in the force-coefficient graphs. These cavities are produced by controlling the parameters $p_{0}$ and $q$ in Eq. (1). Closed cavities obtained by extending control to $p_{k}$ by feeding aix to the wakes of the bodies are indicated by square symbols and are called "artificial." Split cavities, illustrated by photographs in Figs. $8 \mathrm{a}$ and $8 \mathrm{~b}$, occur when a cavity is vented to the surrounding chamber; they are indicated by halfdiamond-shaped symbols. There is an advantage in operating with an artificial cavity because, for the same cavitation number, $q$ can be smaller and $p_{0}$ larger than for a natural cavity. With small $q$ and large $\mathrm{p}_{\mathrm{o}}$, secondary cavitation of the leading edges of the side plates and of the space between , the observation windows can be reduced or eliminated. The experimental data indicate that there is no significant difference between natural and artificial cavities.

Visual observation showed that the cavity walls were generally laminar as they left the test bodies, except in the case of the 2-ino-chord flat plates. The laminar flow became turbulent within about I chord length or less of the trailing ends of the bodies. Transition appeared to occur along a fixed, ragged line across the span on each cavity wall. 
It is desirable to compare the experimental results with theoretical computations. As has already been mentioned in describing the equipment, the uniformity of the velocity across the jet makes it possible to treat the flow as that of an ideal, two-dimensional, infinite jet. A possible limitation on this treatment is the effect of gravity, because the jet is vertical and contracts as it falls. (The contraction effect attributable to gravity is at least partially balanced by boundary-layer growth on the two-dimensional side plates.)

The magnitude of the gravitational effect depends on the velocity, or, more completely, on the Froude number of the jet. This is apparent from the continuity equation, which may be written

$$
\frac{d b}{d h}=-\frac{b}{U} \frac{d U}{d h}
$$

and from the momentum equation

$$
U \frac{d U}{d h}=g
$$

where $h$ is the depth from the origin of the jet to any point in the test section,

$U$ is the velocity, at depth $h$,

$b$ is the breadth of the jet at depth $h$, and

$\mathrm{g}$ is the acceleration due to gravity.

Thus

$$
\frac{d b}{d h}=-\frac{b g}{v^{2}}
$$

For the test jet, $\mathrm{b}$ is 10 inches; with $U=40 \mathrm{fps}$, the theoretical rate of contraction is approximately 0.2 in. per ft of fall while at $20 \mathrm{fps}$, it is 0.8 in. per ft.

In order to estimate the gravitational effect on force coefficients, the flat plate at an incidence of $\tan ^{-1} 0.2$ was operated over a range of 
velocities at each of several cavitation numbers. The resulting lift coefficients are plotted in Fig. 9. Similar results were obtained for drag coefficients. It may be concluded from the figure that within the range of velocities studied, there is no recognizable effect on force coefficients attributable to gravity. Another similar experiment was performed using the wedge of $12.5-$ degree semiangle at zero cavitation number. The results are shown, togethex with other data, in Fig. 4c. A definite decrease in drag coefficient was observed when the velocity was decreased from 27.6 to 19.4 Ips, but at higher velocities any change may be within the experimental exror.

No experimental investigation has been made as to the effect of gravity on cavity shape. The definition for cavitation number given by Eq. (1) may be looked upon as the ratio of transverse momentum change produced by pressure difference to longitudinal momentum change. Considering that, for a given cavitation number, $p_{0}-p_{k}$ is constant along the jet while $U_{0}$ in ereases because of gravity, it would be expected that a cavity in the vertical free jet would be Ionger than predicted by a theory obtained without considering gravitation.

\section{COMPARISON WITH THEORY AND WITH MEASUREMENTS BY OTHERS}

In each of Figs. 3 through 8 , one or more comparable theoretical or experimental results have been introduced.

In Fig. 3, for the two-dimensional cup, the theoretical drag is calculated by assuming that stagnation pressure exists uniformly over the upstream surface of the cup and that cavity pressure exists uniformly over the downstream surface。 Then

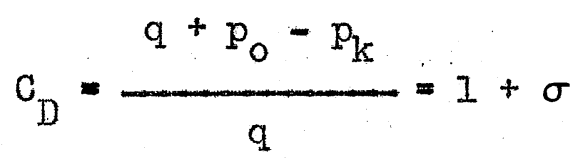

This prediction is independent of the tunnel boundary conditions (but may be influenced by the depth of the cup). The comparison between Eq。 (8) and the experimental results shown in Fig. 3 serves to verify the drag dynamometer.

For the wedges at zero cavitation number in an infinite jet, the free-streamline theory has been worked out by Siao and Hubbard [12]. Calculations have been made from Siao and Hubbard's paper; the theoretical results 
for drag are indicated on the graphs of Fig. 4 and for shape, for the 15degree wedge, by crosses on the photograph of Fig. 8a. Agreement between measurement and theory is very satisfactory. The cavity walls seen in the downstream portion of the photograph in Fig. 8a have already attained their theoretical direction at infinity- 6.42 degrees with the axis of symmetry.

Cohen and $\mathrm{Tu}$ [5] have developed a linearized theory for drag and cavity length of a symmetrical wedge in a free jet at nonzero cavitation numbers. The computations required to obtain drag coefficient from the paper are quite involved, but one of the authors, in a private communication, supplied the curve reproduced in Fig. La for the 15-degree-semiangle wedge... There is good agreement with the experimental data for cavitation numbers above 0.1.* Also reproduced in Fig. 4 a are the infinite fluid theory results obtained by Plesset and Shaffer [9] using the Riabuchinsky method and by Wu [15] using a linearized theory. Wu's results are also plotted in Fig. $4 \mathrm{c}$ for comparison with the experimental results for the 12.5-degree-semiangle wedge. In the noncavitating range ( $\mathrm{Fig} . \mathrm{Hb}$ ) comparisonis made with the experimental results of Lindsey [6] obtained in a closed wind tunnel. The present results are uniformly about 13 per cent below those of Lindsey (which include skin friction).

Theoretical results for cavity length for the 15-degree-semiangle wedge are plotted with the experimental data in Fig. 7a. The effective shortening of the cavity in the free jet as compared to infinite fluid is clearly shown. The measured cavity lengths are even shorter than predicted by the linear free-jet theory, although they might have been expected to be longer because of the gravitational effect discussed in Part IV. Actually, as may be seen in Figs. $8 \mathrm{c}$ and $8 \mathrm{~d}$, there is considerable uncertainty in measuring cavity length and this, together with the breakdown of the linear theory at small cavitation numbers, may account for the discrepancies between experiment and theory.

Although the free-streamline theory for an inclined flat plate in a jet at zero cavitation number is rather straightforward in solution, no

\footnotetext{
* Iinear theories depend on the introduction of a perturbation potential to produce the cavity. It must be assumed that the perturbation potential will not affect the flow at infinity. However, with an infinitely long cavity, there is no way to avoid interference with the flow at infinity and the linear method must fail at zero cavitation number.
} 
solution which had been carried to the point of computational usefulness could

- be found in the literature. Consequently, Appendix B contains such a solution. The resulting theoretical lift and drag coefficients are shown on the graphs ' of Fig. 5, and the resulting cavity shape for the angle of attack of $\tan ^{-1}$ 0.2 is shown on the photograph of Fig. $8 \mathrm{~b}$. Agreement between experiment and theory may again be considered very satisfactory. In the downstream portion of the photograph of $\mathrm{FIg}$. 8b, the cavity walls have already become essentially straight and have attained their theoretical directions at infinity, 4.01 degrees with the axis of symmetry for the wall originating from the leading edge and 6.43 degrees for the other.

There is no available theory for the inclined plate in a jet at nonzero cavitation numbers. * For comparative purposes, the results of Wu's freestreamline theory (nonlinear) in infinite fluid [14] are shown on the graphs of Fig. 5. The data fall below the infinite-fluid theory at small cavitation numbers, as is to be expected, and appear to approach the infinite-fluid results as the cavitation number increases. It should be observed that wu's theoretical results agree well with experimental measurements in a closed tunnel at a chord-tunnel-width ratio of about $1 / 8$ as reported by Parkin [8]. The experimental measurements in the closed tunnel were carried down to a cavitation number of about 0.15 at an angle of attack of 8 degrees, down to about 0.2 at 11 degrees, down to about 0.35 at 20 degrees, and down to about 0.45 at 25 degrees. Insofar as lift is concerned, it appears from the present data, from Wu's theory, and from Parkin's data that wall corrections are important only at small cavitation numbers, of the order of 0.12 or less, for the narrow cavities associated with small angles of attack.

Wu's theory for the plate in infinite fluid does not yield a precise definition of cavity length. However, lengths obtained using the definition given by wu are shown for comparative purposes on the graphs of Figs. $7 \mathrm{c}$ and 7d. Also shown on these graphs are the cavity lengths predicted by Tulin's [13] Iinear theory for the inclined plate in infinite fluid. (Iift and drag predicted by Tulin's theory were not shown in Fig. 5 as the curves are only a little higher than Wu's curves at zero cavitation number and approach Wu's curves closely at higher cavitation numbers.) As in the case of

*There is a fundamental obstacle to the development of a suitable Iinear theory for a lifting surface in a jet because of the absence of symmetry in both the cavity and the jet walls. 
the wedge, there is difficulty in selecting the closing point of the cavities from the flat-plate photographs, so the experimental cavity lengths shown in the figures are subject to some exror. The results look reasonable, however, when compared with the infinite-fluid theory.

The theoretical point for the circular cylinder at zero cavitation number, shown in Fig. 6a, is taken from Brodetsky's solution for infinite fluid [3]. The experimental data, falling slightly below Brodetsky's prediction, are at least qualitatively in good agreement with theory. At higher cavitation numbers, shown in Fig. 6b, comparison is made with Martyrer's experimental data [7] obtained in a closed tunnel. Again, agreement between the free-jet and closed-tunnel results is reasonably good. For the noncavitating flow past the circular cylinder, FIg. 6c, the accepted value for the drag coefficient at Reynolds numbers from 2 to $4 \times 10^{4}$ is about 1.2 as given in Prandt 1 and Tietjens [10]. Small discrepancies between free-jet and closedtunnel results may be accounted for by variations in the point of separation on the cylinder.

\section{SUIMUARY}

Good agreement has been obtained between measurements in the freejet tunnel and theoretical prediction for a free jet, where theoretical predictions were available. At the operating speeds of the tumel, gravitation has no effect on the measured force coefficients. The tumel and measuring equipment are, therefore, believed to be operating satisfactorily.

Comparison between the present results and theoretical results for infinite fluid or measurements by others in closed tunnels indicates that wall corrections for converting measured results in the free jet to infinite-fluid conditions are negligibly. small for all but the smallest cavitation numbers. At zero cavitation number, force coefficients and cavity lengths measured in the free jet can be expected to be less than those in infinite fluid. The exact relation depends on the shape of the body and its position in the jet. For the flat plate at several angles of attack, the difference between the measurements in the jet and the theoretical predictions for infinite fluid all but disappeared for cavitation numbers greater than about 0.12 . 


\section{ACKNOWLEDGMENTS}

The work described herein was supported by the Office of Naval Research, United States Department of the Navy, under contract Nonr 710(24). Robert $I$. Gordier has been responsible for operating the tunnel and obtaining the experimental data. John F. Ripken has been of material assistance in perfecting the experimental equipment and in offering advice on other phases of the work. 


$$
\underline{I} \underline{\underline{S}} \underline{\mathrm{T}} \quad \underline{O} \underline{\mathrm{F}} \quad \underline{\mathrm{R}} \underline{\mathrm{E}} \underline{\mathrm{F}} \underline{\mathrm{E}} \underline{\mathrm{R}} \underline{\mathrm{E}} \underline{\mathrm{N}} \underline{\mathrm{C}} \underline{\mathrm{E}} \underline{\mathrm{S}}
$$

[1] Birkhoff, $G_{0}$, Plesset, $M_{0}$, and Simmons, $N_{0}$ "Wall Effects in Cavity Flow--I." Quarterly Applied Mathematics, 8, Section 2, pp. 151-168. 1950。

[2] Birkhoff, $G_{0}$, Plesset, $M_{0}$, and Simmons, No. "Wall Effects in Cavity Flow--II." Quarterly Applied Mathematics, 9, pp. 413-42I.

[3] Brodetsky, So "Discontinuous Fluid Motion Past Circular and Elliptic Cylinders." Proceedings of the Royal Society, London, Series A, Vol. 102, pp. 542-553。 1922-23。

[4] Christopherson, C. D. Description of a Ten-Inch Free-Jet Water Tunnel. University of Minnesota, St. Anthony Falls Hydraulic Laboratory Project Report No. 35, 1953. 47 pages. (Available on interlibrary loan at the University of Minnesota Libraxy, Minneapolis 14, Minnesota.)

[5] Cohen, $\mathrm{H}_{0}$, and $\mathrm{Tu}$, Yih-O. "A Comparison of Wall Effects on Supercavitating Flows Past Symmetric Bodies in Solid Wall Channels and Jets." Proceedings of the Ninth International Congress of Applied Mechanics, Brussels, pp. 359-370. 1956.

[6] Lindsey,W. F. "Drag of Cylinders of Simple Shapes." National Advisory Committee for Aeronautics, Report No.619, 1938. 8 pages.

[7] Martyrer, E. "Kraftsmessungen an Widerstands Körpern und Flügelprofilen in Wasserstrom beiz Kavitation." Hydromechanische Probleme des Schiffsentriebs, Ed.by G. Kempf and E. Foerster, Hamburg, pp.268-286。1932。

[8] Parkin, B. R。 "Experiments on Circular Arc and Flat Plate Hydrofoils in Noncavitating and Full Cavity Flows." Journal of Ship Research, Vol. I, pp. 34-56. 1958。

[9] Plesset, M. So, and Shaffer, P. A., Jr. "Cavity Drag in Two and Three Dimensions." Journal of Applied Physics, Vol. 19, pp. 934-939. 1948.

[10] Prandtl, I., and Tietjens, 0. G. Applied Hydro and Aeromechanics. New York: MeGraw-Hili, 1934. Fig. 50 p. 96.

[I]] Schlichting, H• Boundary Layer Theory. New York: McGraw-Hill, 1955. pp. 128-129.

[12] Siao, T. To, and Hubbard, $P_{0} G_{0}$ "Deflection of Jets--I. Symmetrically Placed V-Shaped Obstacle." Free Streamline Analyses of Transition Flow and Jet Deflection. State University of Iowa, Bulletin No. 35, pp. 33-44. 1953.

[13] Tulin, M. P. "Supercavitating Flow PastFoils and Struts。" Proceedings of Symposium on Cavitation in Hydrodynamics, Paper No. 16, 
Teddington, England: National Physical Laboratory, 1956. 19 pages.

[14] Wu, T. Y. "A Free Streamline Theory for Two-Dimensional Fully Cavitated Hydrofoils." Journal of Mathematics and Physics, Vol. XXXV, pp. 236-265. 1956.

[15] Wu, T. Y. A Simple Method for Calculating the Drag in the Linear. Theory of Cavity Flows. California Institute of Technology, Report No. 85-5, 1957. 24 pages. 
$\underline{F} \underline{I} \underline{G} \underline{\mathrm{U}} \underline{\mathrm{R}} \underline{\mathrm{E}} \underline{\mathrm{S}}$

(1 through 9) 

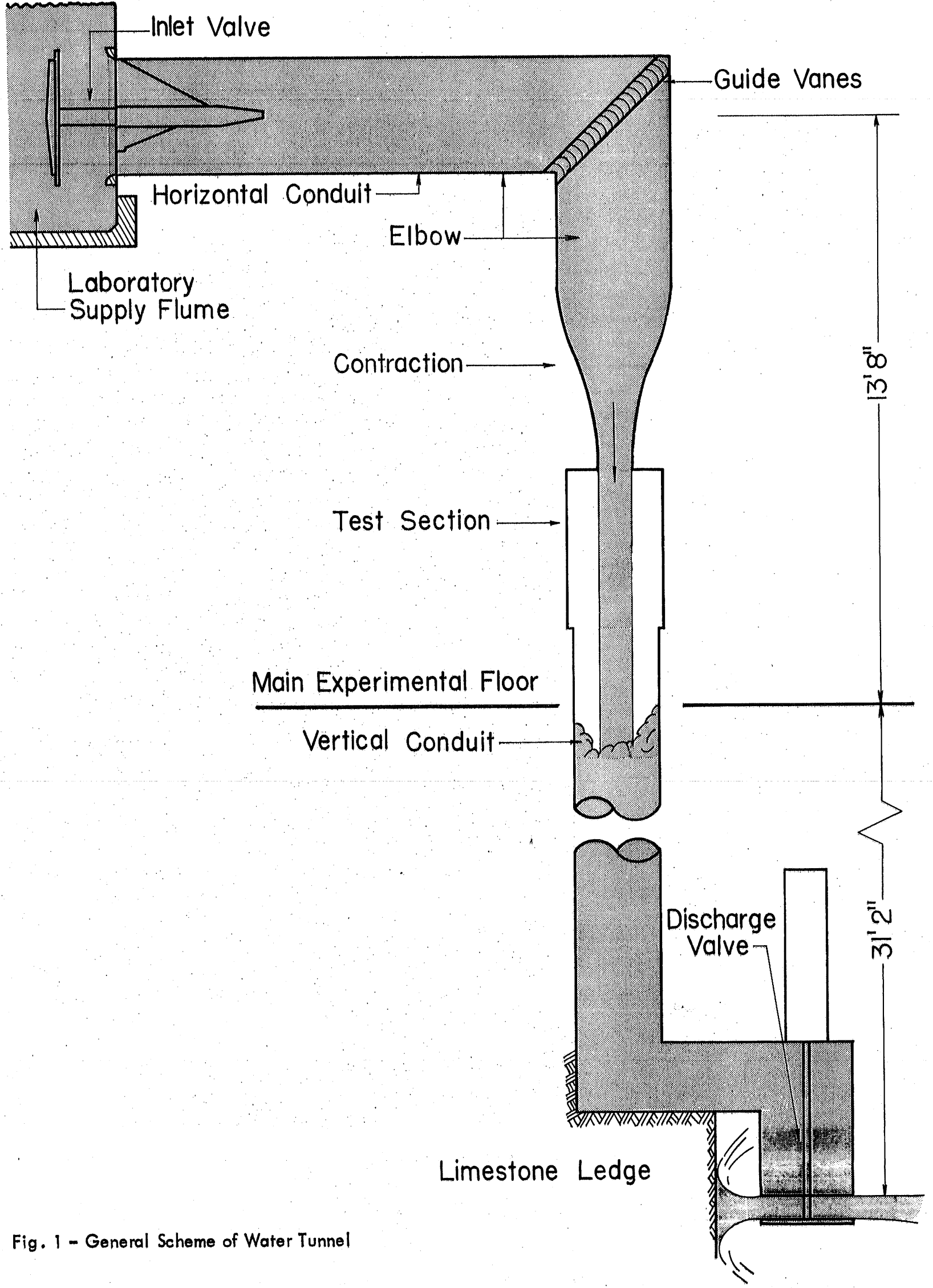

Fig. 1 - General Scheme of Water Tunnel 


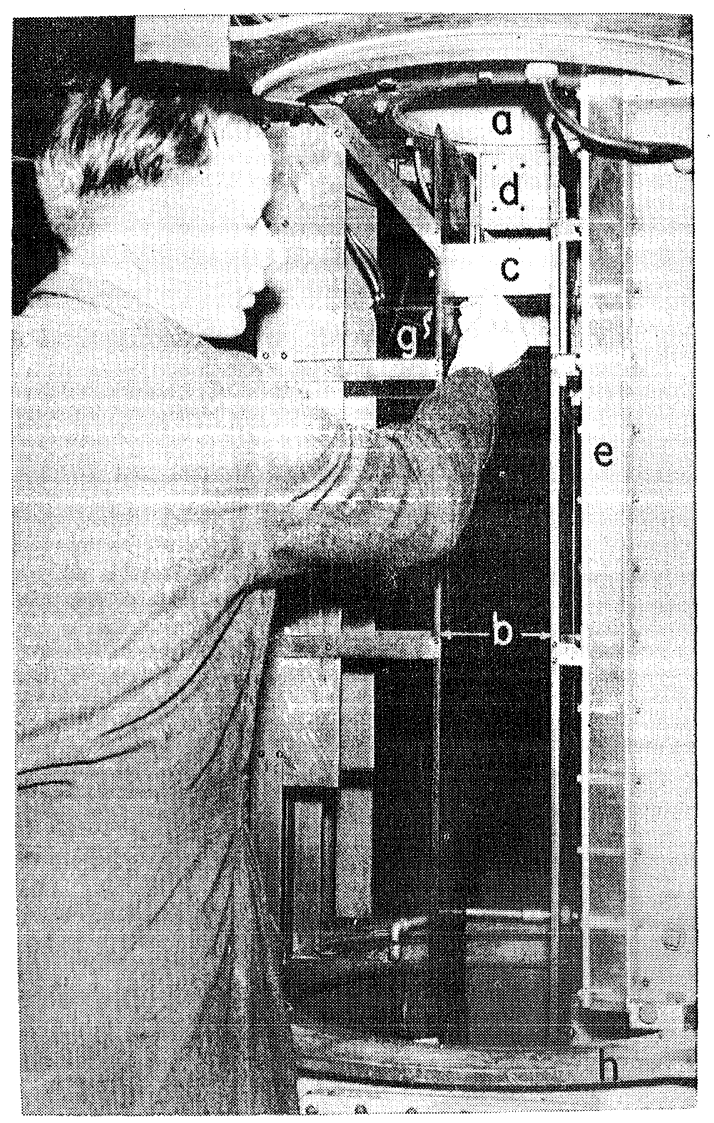

a. 10-in. Dia. Free Jet Nozzle

b. Two Dimensional Side Plates

c. Test Body and Integral End Disks

d. Side Plate Support Structure

e. Viewing Window (Plexiglass)

f. Dynamometers

g. Piezometer Tubes for Measuring Cavity Pressure

h. Housing that Rises to Seal Test Section

\section{ELEVATION}

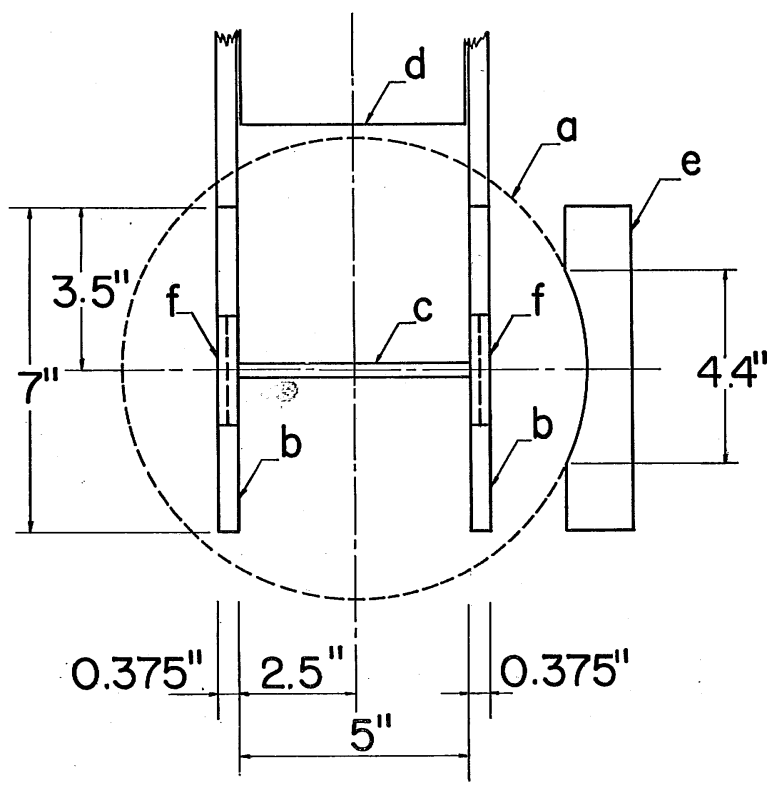

PLAN

Fig. 2 - Views of Two-Dimensional Test Section 


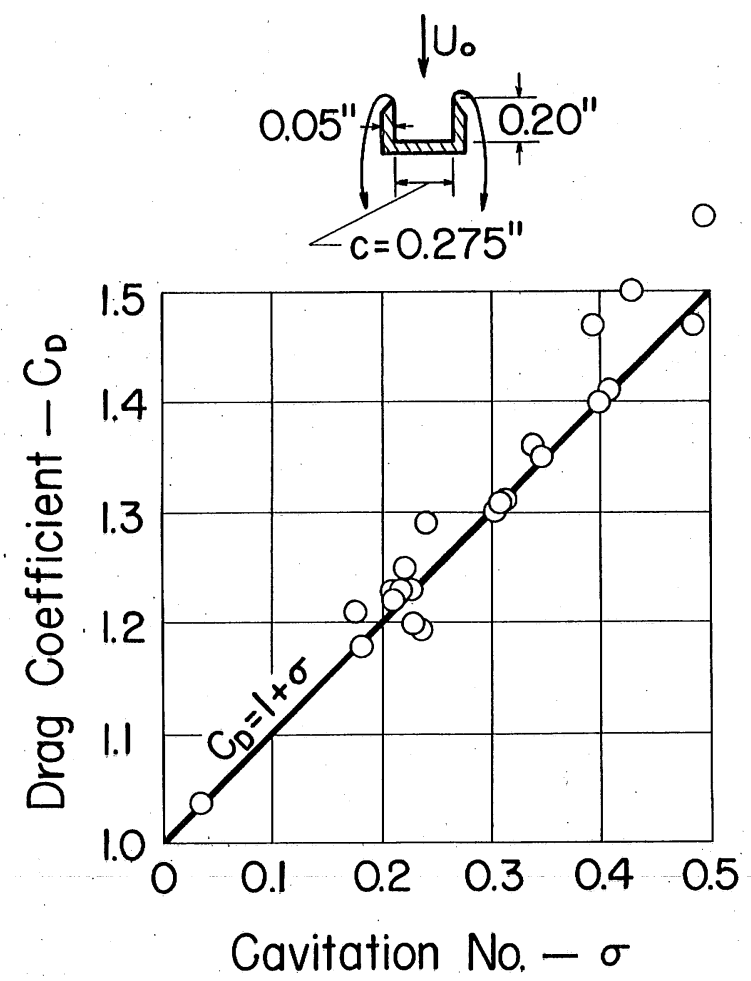

Fig. 3 - Drag Coefficient for Two-Dimensional Cup 

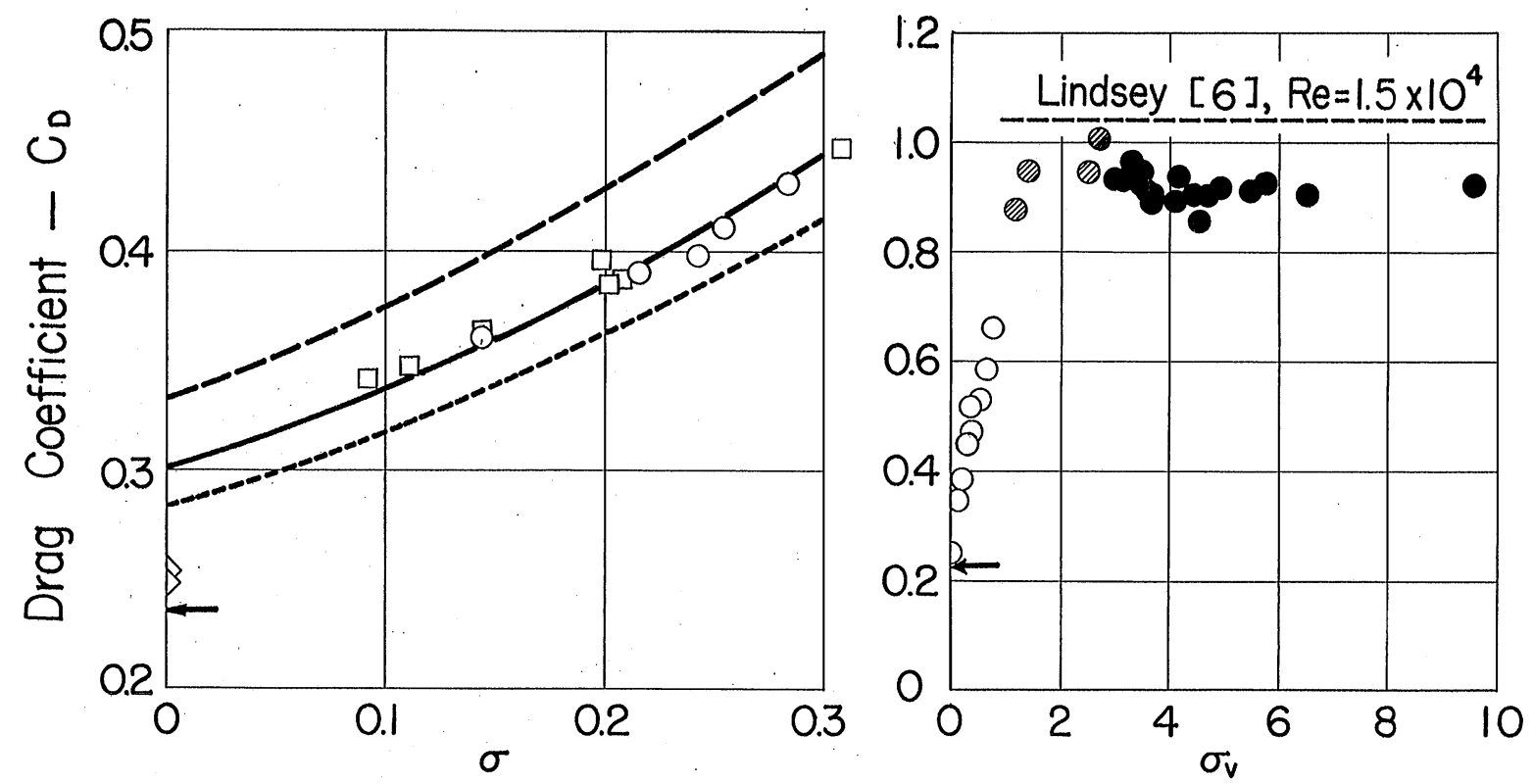

Cavitation Number

a. $\quad \gamma=15$ deg., Small $\sigma$

b. $\quad \gamma=15$ deg., Large $\sigma$
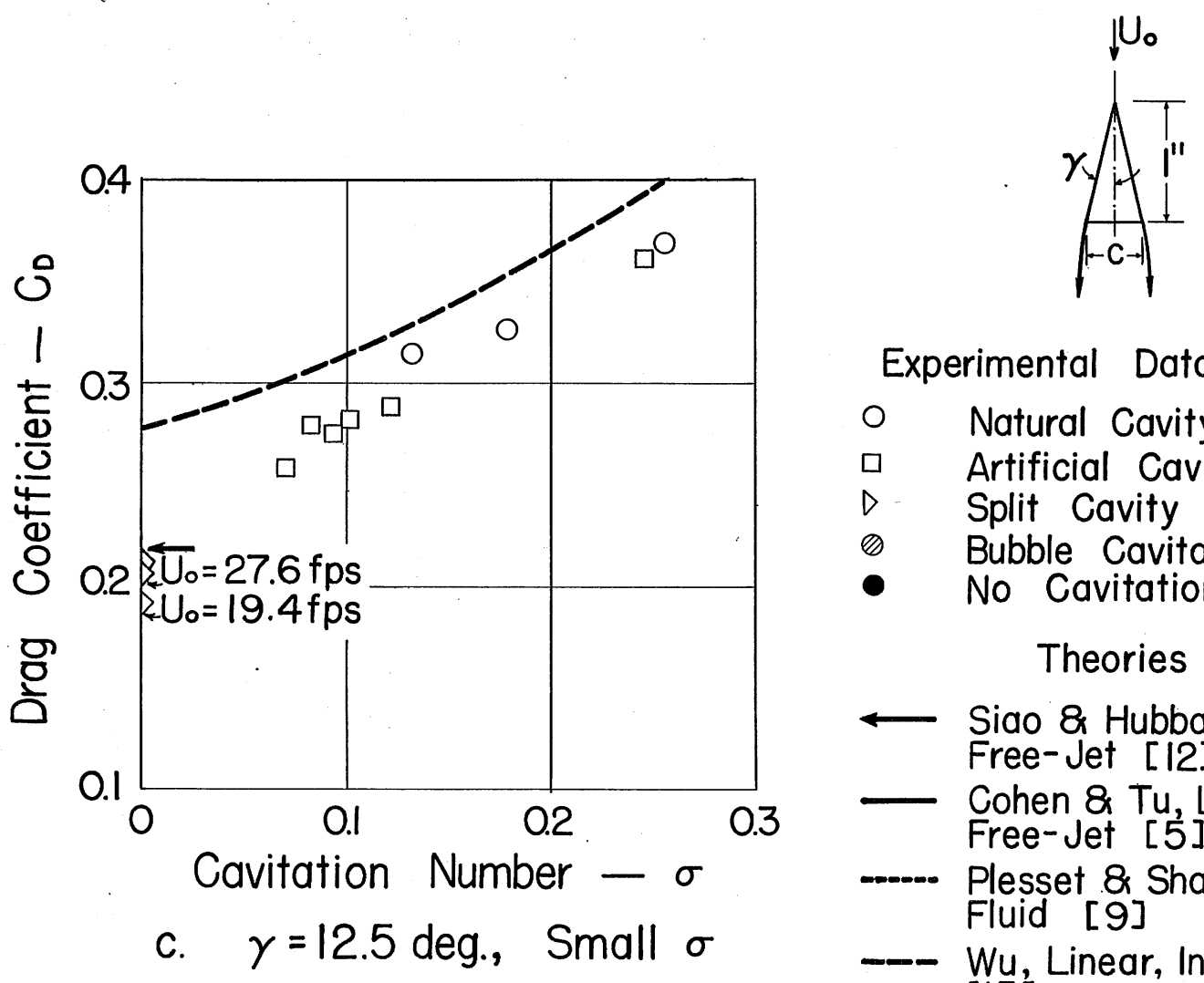

Experimental Data

- Natural Cavity

․ Artificial Cavity

$D$ Split Cavity

- Bubble Cavitation

- No Cavitation

Theories

$\longleftarrow$ Siao \& Hubbard, Exact, Free-Jet [12]

Cohen \& Tu, Linear, Free-Jet [5]

Plesset \& Shaffer, Infinite Fluid [9]

- - Wu, Linear, Infinite Fluid [15]

Fig. 4 - Drag Coefficients for Symmetrical Wedges 


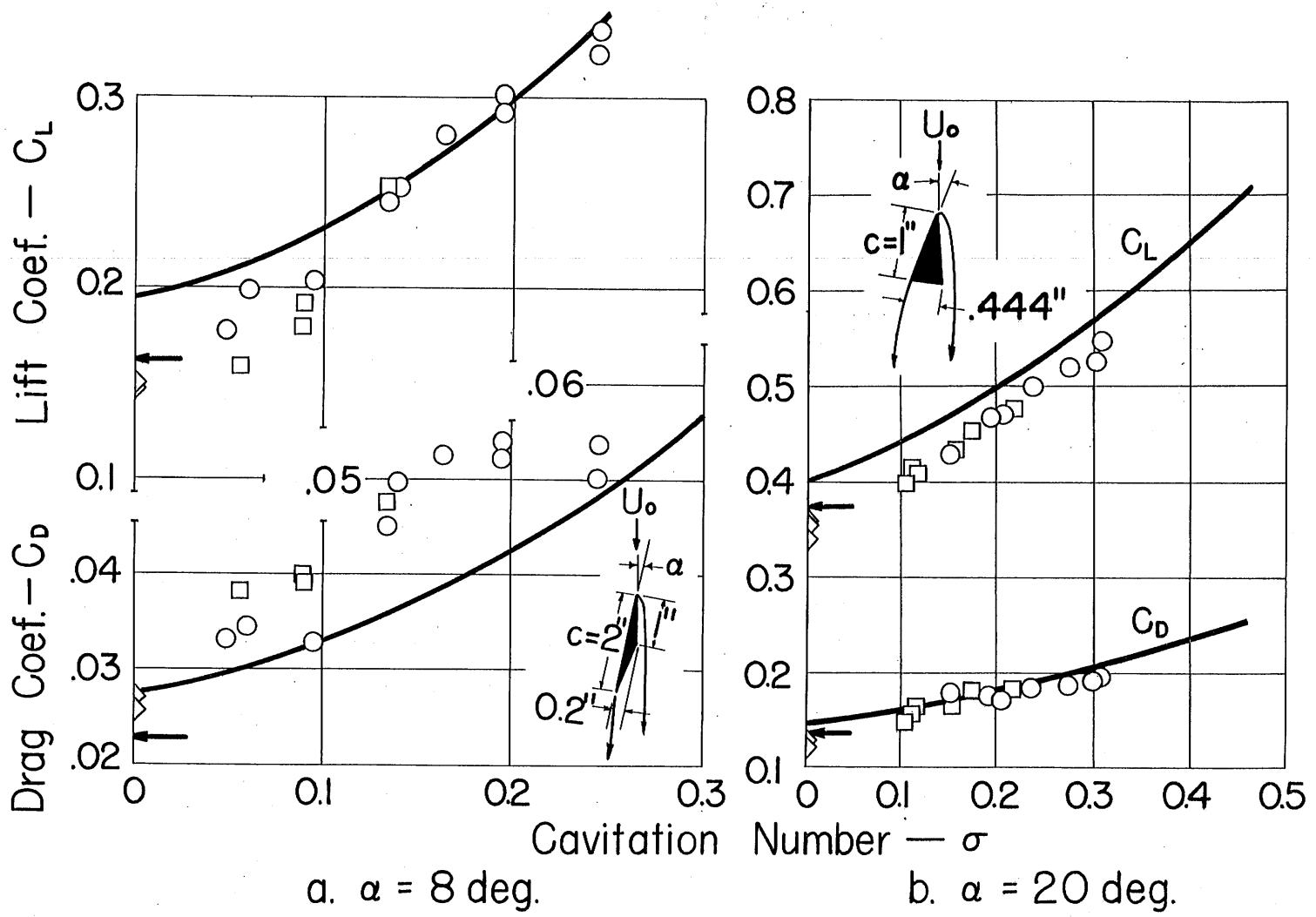

—Exact, Free-Jet Theory; - Wu, Inf. Fluid Theory [14], See Exper. Legend Fig.4
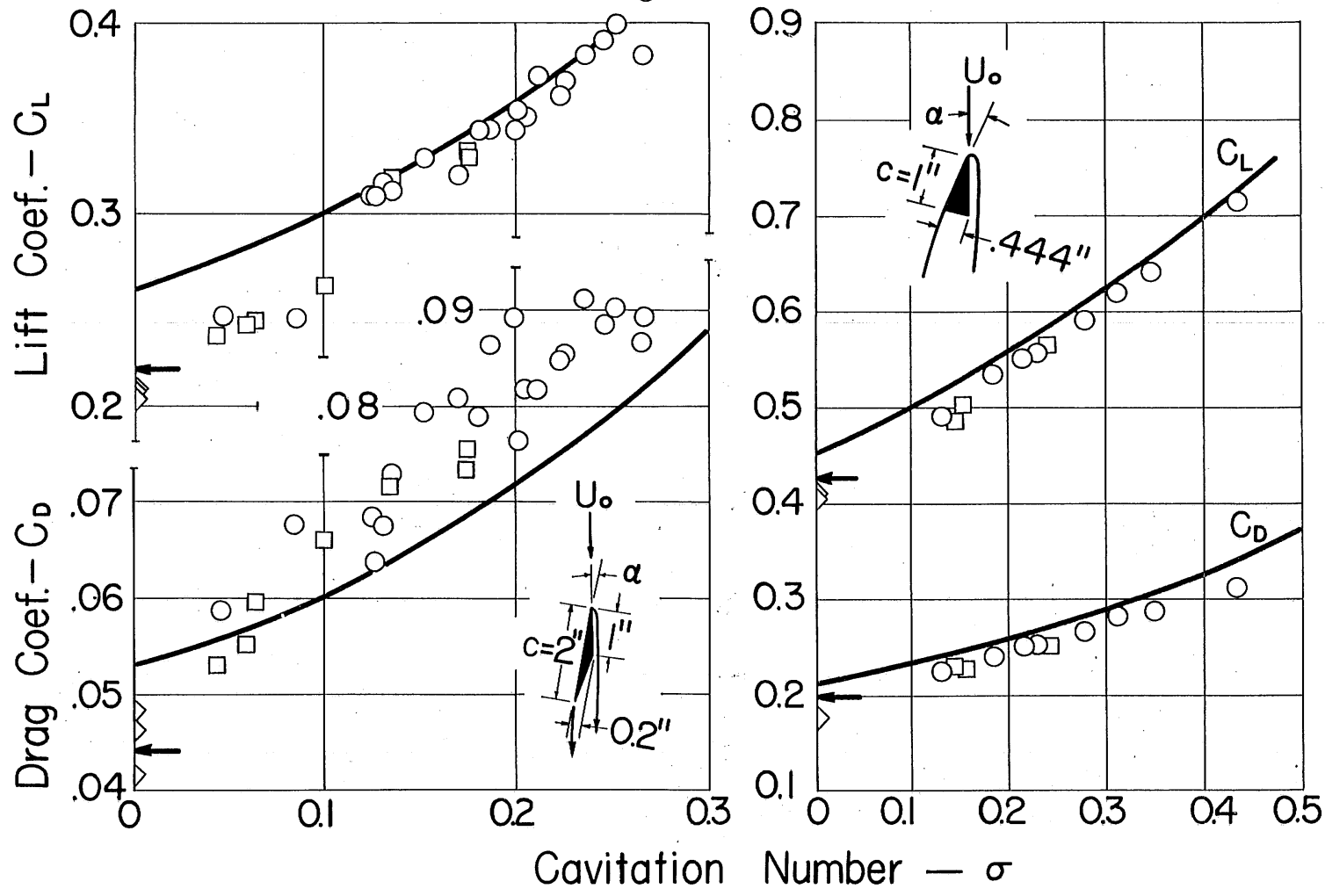

c. $\alpha=\tan ^{-1} 0.2$

d. $\alpha=25$ deg.

Fig. 5 - Lift and Drag Coefficients for Inclined Flat Plates 


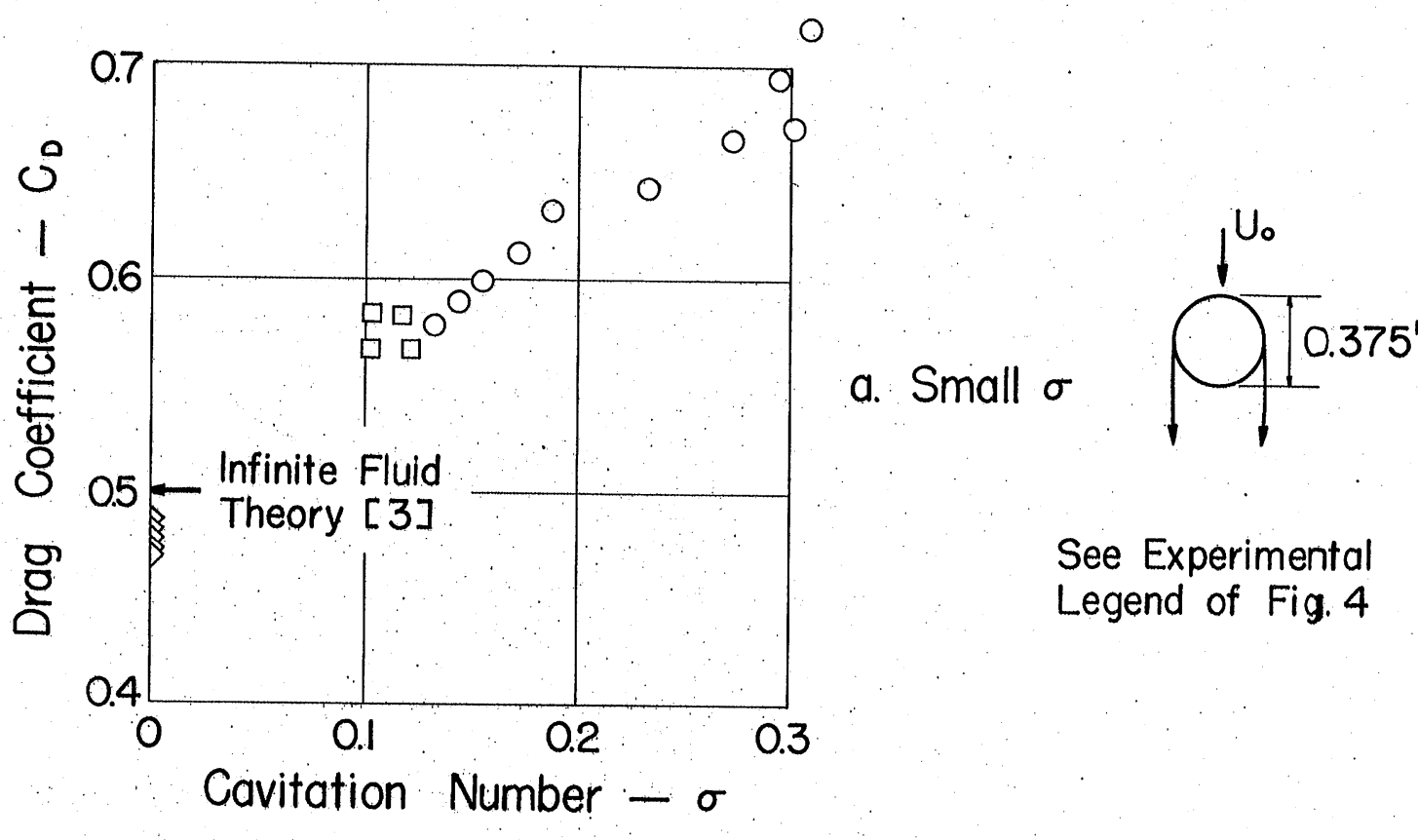

b. Large $\sigma$

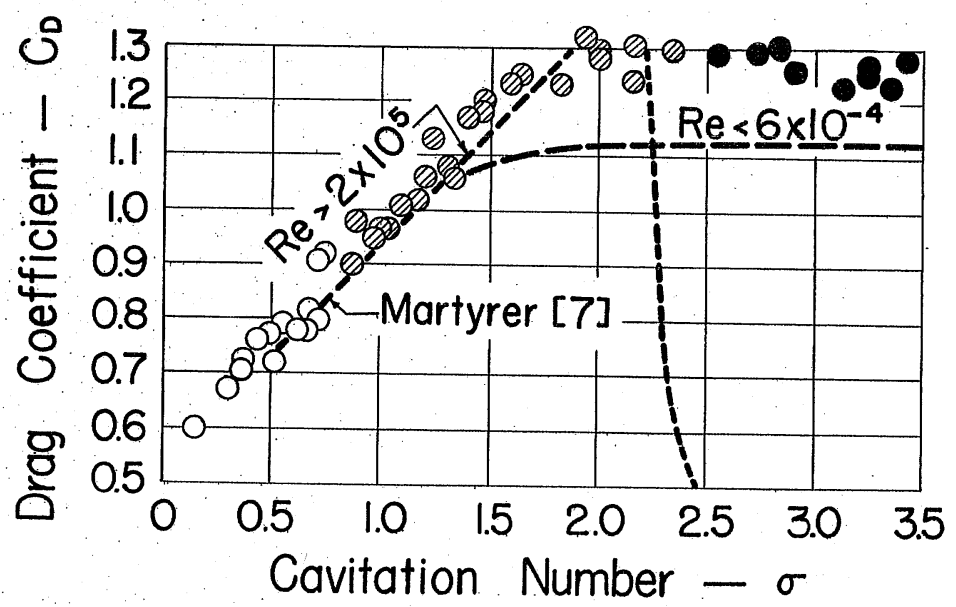

c. As a Function of Reynolds Number

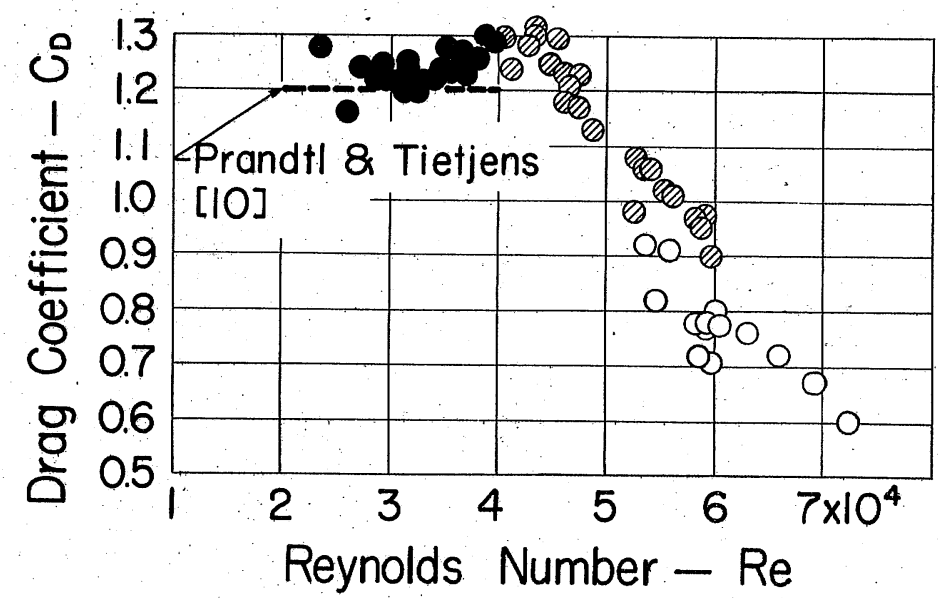

Fig. 6-Drag Coefficient for Circular Cylinder 


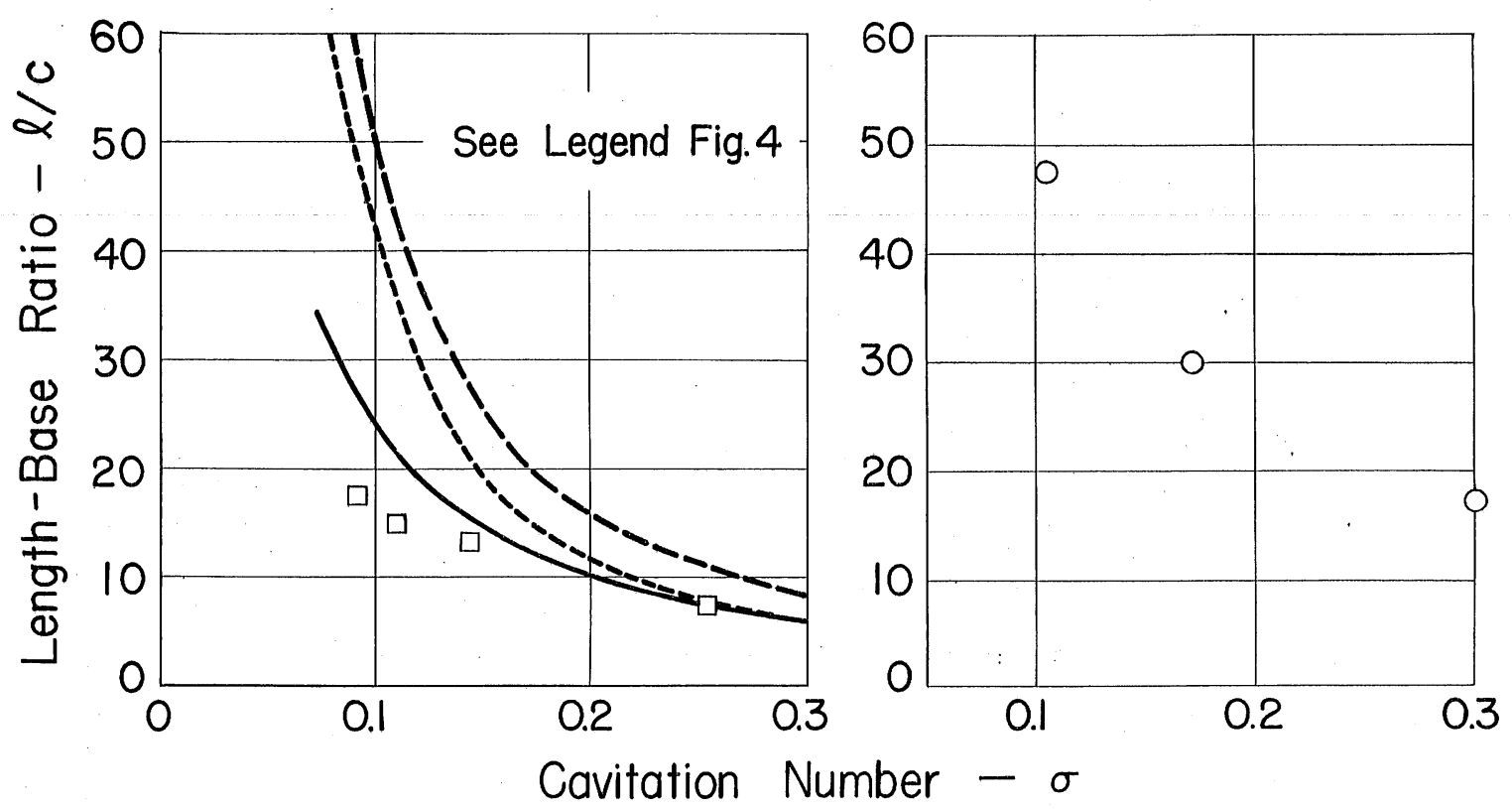

a. Symmetrical Wedge, $\gamma=15 \mathrm{deg}$. b. Circular Cylinder

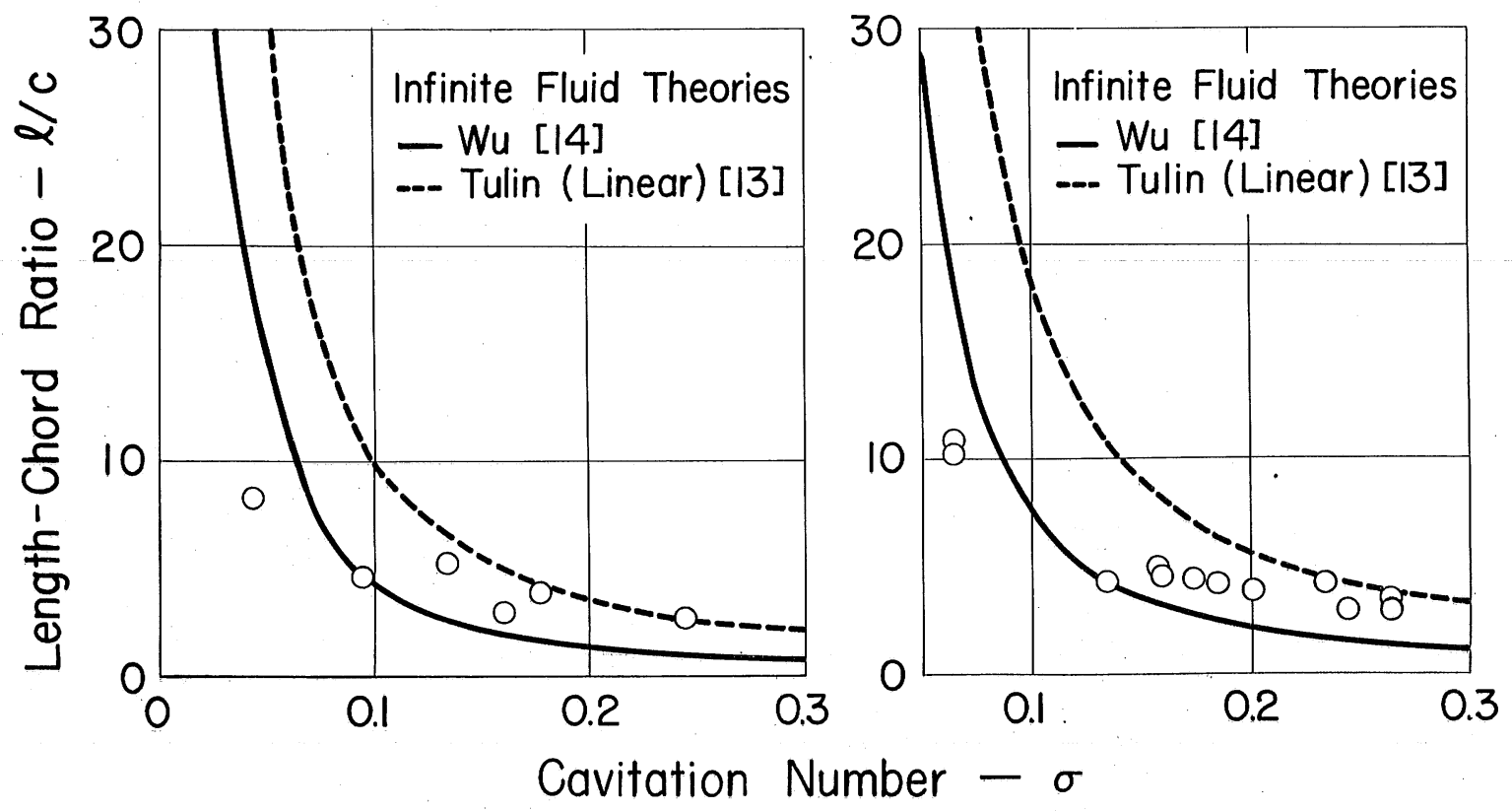

c. Flat Plate, $\alpha=8 \mathrm{deg} \quad$ d. Flat Plate, $\alpha=\tan ^{-1} 0.2$

Fig. 7 - Typical Cavity Length Measurements 


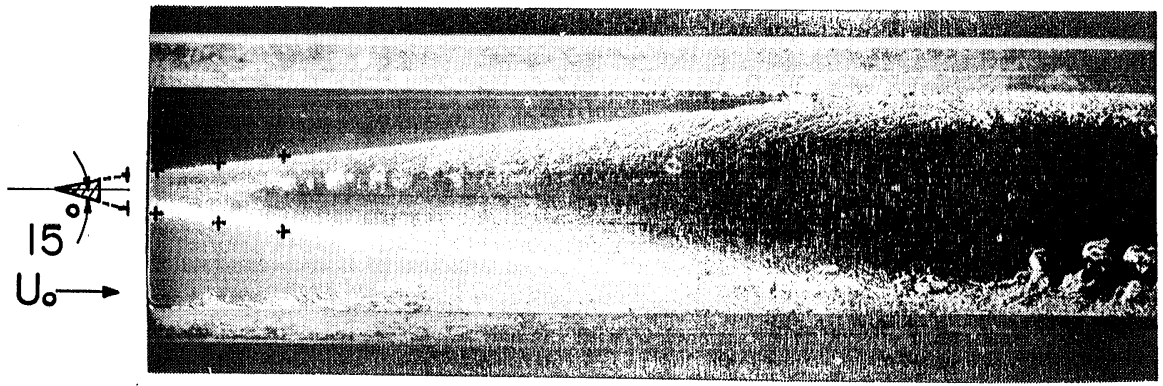

- Theoretical Points

a. Symmetrical Wedge, $\sigma=0$

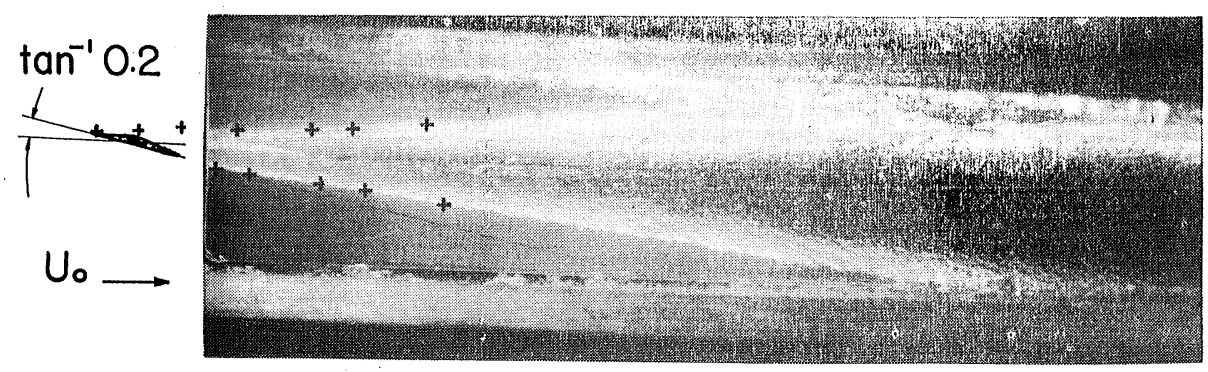

- Theorefical Points
b. Flat Plate
$\sigma=0$

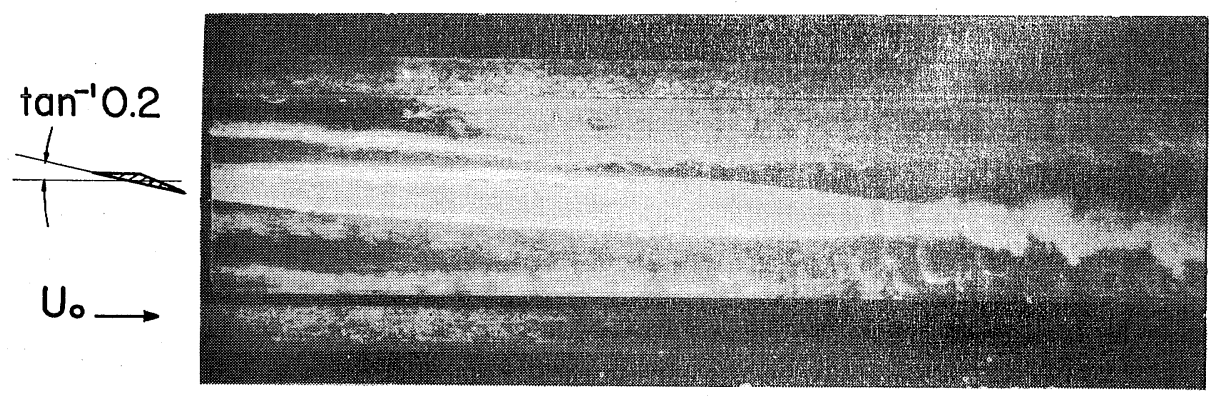
c. Flat Plate
$\sigma=0.063$

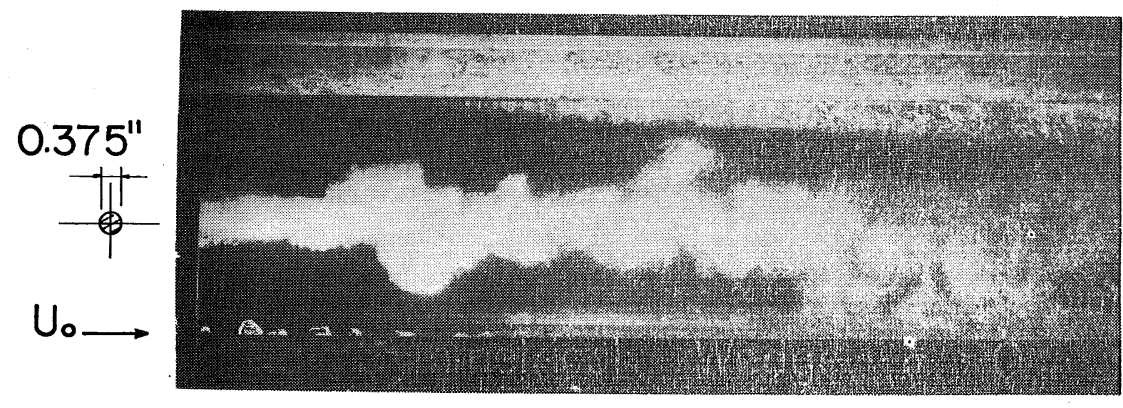
d. Circular
Cylinder
$\sigma=0.301$

Fig. 8 - Typical Cavities 


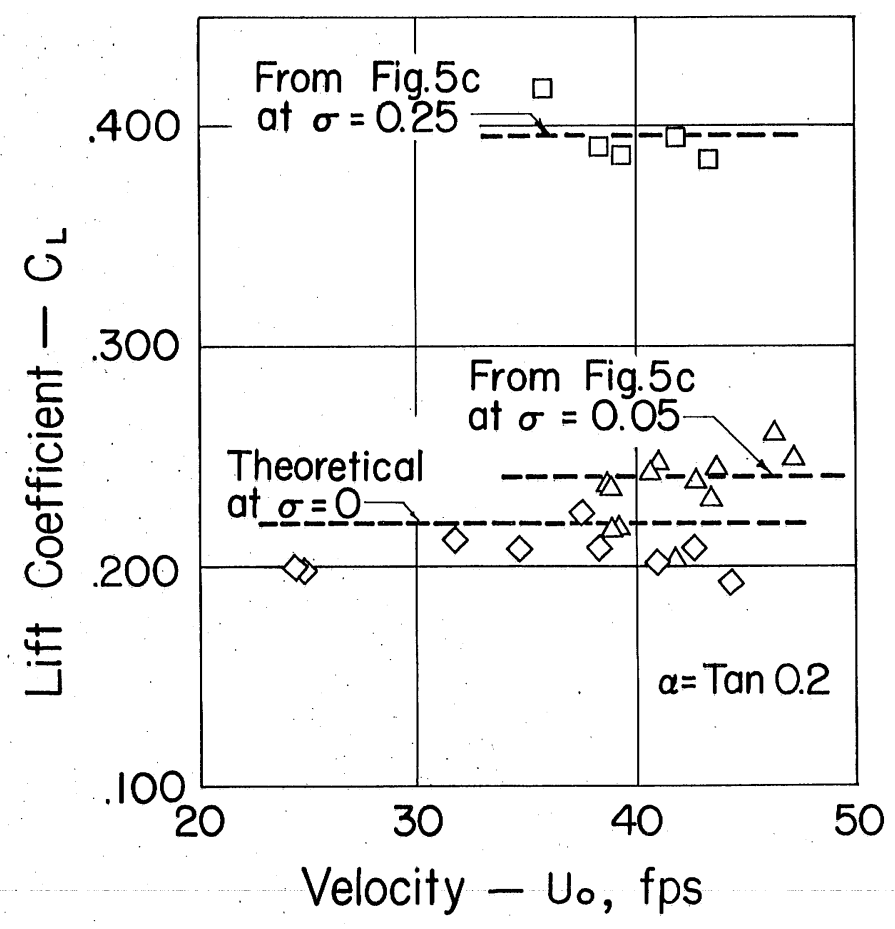

Fig. 9 - Effect of Gravity on Flat-Plate Lift Coefficient 
$\underline{A} \underline{P} \underline{-} \underline{N} \underline{D} \underline{X} \quad \underline{A}$

DRAG CORRECTIONS 


\section{$\underline{A} \underline{P} \underline{P} \underline{N} \underline{D} \underline{X} \quad \underline{A}$}

\section{DRAG CORRECTIONS}

Two subtractive corrections were made to the measured drag coefficients. The first of these, the end-disk drag, was calculated by assuming a turbulent (dictated by the Reynolds number) flat-plate boundary layer from the leading edge of each side plate. The local shear stress was then integrated over the area of each disk less an average area occupied by the body plus cavity or wake. No allowance was made for pressure drag on the disks even though therewas a little leakage around their edges. The final expression for the correction to the drag coefficient for the two end disks was

$$
\Delta C_{D}=-\frac{0.0605}{R e^{I / 5}}\left(\frac{R}{c}\right)^{4 / 5}
$$

where $R$ is the radius of the end disk--1.27 inches.

The calculations were partially checked by measurements in the tunnel. Aflat plate of 2 -in. chord and at an incidence of $\tan ^{-1} 0.2$ was mounted rigidly as a cantilever beam from the lift side plate with the lift dynamometer removed. A dummy end disk was mounted in the drag dynamometer about 0.004 in. separated the disk from the flat plate. Drag measurements obtained with this arrangement were about 25 per cent lower than given by the above formula. It was later realized, however, that pressure differences over the face of the disk caused the disk to twist out of the plane of the wall, twisting the dynamometer and producing false readings which could be expected to be low.

The second correctionwas for skin-friction drag on the test bodies. The wedges, being of 1-in. chord, possessed laminar boundary layers. Drag was calculated using the wedge-flow solution as outlined in Schlichting [11]. For application of this solution, the velocity was taken in the form

$$
U(x)=U_{k} x^{m}=U_{0}(I+\sigma)^{I / 2} x^{m}
$$

where $x$ is the distance along the wedge from the front stagnation point, in inches $(0 \leq x \leq 1)$, 
$\mathrm{U}(\mathrm{x})$ is the velocity at any $\mathrm{x}$,

$U_{k}$ is the constant velocity at the edge of the cavity given by $\left(\mathrm{U}_{\mathrm{k}} / \mathrm{U}_{\mathrm{o}}\right)^{2}=1+\sigma$, and

$m=y /(\pi-\gamma)$ where $y$ is the wedge semiangle.

Integration of the wall-shear stress over both surfaces resulted in the expression

$$
\Delta C_{D}=-C \frac{(1+\sigma)^{3 / 4}}{R e^{I / 2}}
$$

where the constant $\mathrm{C}$ has the value 1.91 for the 12.5-degree-semiang.le wedge and 2.20 for the 15-degree-semiangle wedge. It is noted in passing that if each wedge surface had been considered a flat plate at zero pressure gradient in a stream of velocity $\mathrm{U}_{0}$, the constants would have been 1.77 and 1.94, respectively, at zero cavitation number.

In view of the wedge solution and the comparisonwith the flat plate at zero pressure gradient just discussed, skin friction on the inclined flat plates (one side only) was based on the skin friction of the flat plate at zero pressure gradient. For laminar boundary layers, Eq. (A-3) was used, C having the value 1.328. For turbulent boundary layers, which occurred on the 2-in.-chord plate, $0.074 / \mathrm{Re}^{1 / 5}$ was substituted in $\mathrm{Eq}$. $(\mathrm{A}-3)$ for $\mathrm{C} / \mathrm{Re}^{1 / 2}$.

Only the end-disk skin-friction correction was applied to the cup and circular cylinder data. 
A $\underline{P} \underline{P} \underline{E} \underline{\mathbb{N}} \underline{\underline{I}} \underline{\mathrm{X}} \quad \underline{B}$

FREE-STREAMIINE SOLUTION FOR AN INCLINED FLAT PIATE IN AN INFINITE JET 


\section{$\underline{A} \underline{P} \underline{P} \underline{E} \underline{N} \underline{D} \underline{I} \underline{X} \quad \underline{B}$}

FREE-STFEAIILINE SOLUTION FOR AN INCLINED FLAT PLATE IN AN INFINITE JET

The upper diagram in Fig. B-I represents the flow from a jet from a nozzle about an inclined flat plate. The corresponding complex-potential plane and other mapping planes are shown in the remaining diagrams. The origin in the physical plane is taken at the stagnation point A. The angle of attack is $a$ and the velocity on the free streamline is $U_{0}$. The transformations are:

$$
\left.\begin{array}{c}
W=\frac{m U_{0} h}{\pi}\left[n \ln \frac{\zeta-e}{e+a}+\ln \frac{\zeta+e l}{e^{\prime}-a}-i \pi n\right] \\
n=\frac{e+a}{e^{1-a}} \\
\frac{d Q}{d \zeta}=\frac{K}{(\zeta+a)\left[\left(\zeta^{2}-1\right)(\zeta-d)\left(\zeta+d^{\prime}\right)\right]^{1 / 2}}
\end{array}\right\}
$$

Equation $(B-2)$ is readily integrated when points $D$ and $D^{\prime}$ are at infinity in the $\zeta$ plane ( $p$ goes to infinity in the physical plane while $h+n h$ remains constant). This corresponds to the case of the infinite jet with $m=1$. Then

$$
\begin{aligned}
& \theta=-\cosh ^{-1}\left(\frac{1+a \zeta}{\zeta+a}\right)=-\ln \left\{\frac{1+a \zeta}{\zeta+a}-\left[\left(\frac{1+a \zeta}{\zeta+a}\right)^{2}-1\right]^{1 / 2}\right\} \\
& -U_{0} \frac{d z}{d w}=\frac{1+a \zeta+i\left[\left(1-a^{2}\right)\left(\zeta^{2}-1\right)\right]^{1 / 2}}{\zeta+a} \\
& a=\cos \alpha \\
& \left.\begin{array}{c}
\beta=-\alpha+\tan ^{-1}\left[\frac{\left(e^{2}-1\right)^{1 / 2} \sin \alpha}{1+e \cos \alpha}\right], \\
\beta^{\prime}=-\alpha+\tan ^{-1}\left[\frac{\left(e^{2}-1\right)^{1 / 2} \sin \alpha}{e^{\prime} \cos \alpha-1}\right]
\end{array}\right\}
\end{aligned}
$$




$$
\frac{d z}{d \zeta}=-\frac{h(n+1)}{\pi} \frac{1+a \zeta+\left(1-a^{2}\right)^{1 / 2}\left(1-\zeta^{2}\right)^{1 / 2}}{(\zeta+01)(\zeta-0)}
$$

and for $\zeta^{2} \leq 1$

$$
\begin{aligned}
& \frac{z}{h(n+1)}=\frac{1}{\pi\left(e^{\prime}+e\right)}\left[(a e+1) \ln \frac{a+e}{e-\zeta}-\left(a e^{\prime}-1\right) \ln \frac{e^{\prime}+\zeta}{e^{\prime}-a}\right]+\frac{\sin a}{\pi}\left\{\pi-a-\cos ^{-1} \zeta\right. \\
& +2 \frac{\left(e^{2}-1\right)^{1 / 2}}{e^{\prime}+e} \tan ^{-1} \frac{[(1-a)(1-\zeta)]^{1 / 2}-[(1+a)(1+\zeta)]^{1 / 2}}{\left[(1-a)(1+\zeta)\left(e^{\prime}+1\right) /\left(e^{\prime}-1\right)\right]^{1 / 2}+[(1+a)(1-\zeta)(e \prime-1) /(e+1)]^{1 / 2}} \\
& \left.+2 \frac{\left(e^{2}-1\right)^{1 / 2}}{e^{\prime}+e} \tan ^{-1} \frac{[(1-a)(1-\zeta)]^{1 / 2}-[(1+a)(1+\zeta)]^{1 / 2}}{[(1-a)(1+\zeta)(e-1) /(e+1)]^{1 / 2}+[(1+a)(1-\zeta)(e+1) /(e-1)]^{1 / 2}}\right\}
\end{aligned}
$$

The constant was evaluated so that $z=0$ when $\zeta=-a$. Noting that the chord length is given by $c=z_{B},-z_{B}$, the chord-length to jet-width ratio is

$$
\frac{c}{h(n+1)}=\left[1-\frac{\left(e^{2}-1\right)^{1 / 2}+\left(e^{2}-1\right)^{1 / 2}}{e^{\prime}+e}\right] \sin \alpha-\frac{a e^{\prime}-1}{\pi\left(e^{\prime}+e\right)} \ln \frac{e^{\prime}+1}{e^{\prime}-1}+\frac{a e+1}{\pi\left(e^{\prime}+e\right)} \ln \frac{e+1}{e-1}
$$

For $\zeta^{2} \geq 1$, the integral of $\mathrm{Eq} \cdot(\mathrm{B}-7)$ may be written

$$
\begin{aligned}
& \frac{z}{h(n+1)}=\frac{1}{\pi\left(e^{\prime}+e\right)}\left[\left(a e^{\prime}-1\right) \text { en } \frac{e^{\prime}-a}{e^{\prime}+\zeta}-(a e+1) \text { en } \frac{e-\zeta}{a+e}\right]-\frac{a}{\pi} \sin \alpha
\end{aligned}
$$

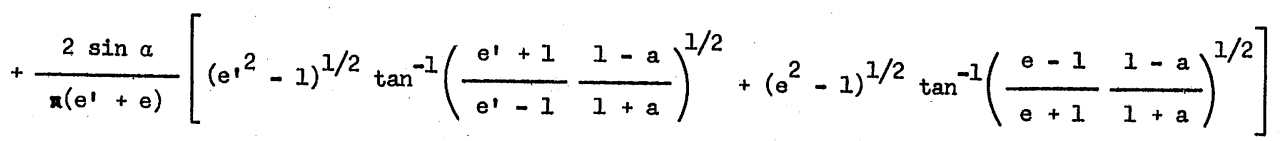

$$
\begin{aligned}
& +i \frac{\sin \alpha}{\pi} \cosh ^{-1}\left\{(-5)-\frac{2}{e^{\prime}+e}\left[\left(e^{2}-1\right)^{1 / 2} \tanh ^{-1}\left(\frac{e^{\prime}+1}{e^{\prime}-1} \frac{\zeta+1}{\zeta-1}\right)^{1 / 2}+\left(e^{2}-1\right)^{1 / 2} \tanh ^{-1}\left(\frac{e-1}{e+1} \frac{\zeta+1}{\zeta-1}\right)^{1 / 2}\right]\right\}
\end{aligned}
$$

The positions of the upper and lower jet walls at $E$ with respect to $A$ in the physical plane are given by

$$
1 / 2 n(h+1)-(t-r) \sin \alpha=-x_{E}(-\infty) \sin \alpha-y_{E}(-\infty) \cos \alpha
$$




$$
1 / 2 n(h+1)+(t-r) \sin \alpha=x_{E(+\infty)} \sin \alpha+y_{\mathbb{E}(+\infty)} \cos \alpha
$$

Subtracting Eq. (B-II) from Eq. (B-12),

$$
\begin{aligned}
& \frac{t}{h(n+1)}=1 / 2 \sin \alpha+\frac{\cos \alpha}{\pi} \ln 2+\frac{1}{e^{\prime}+e}\left\{\cot \alpha-\left(e^{\prime}-e\right) \frac{\sin \alpha}{2}-\left(e^{2}-1\right) \sin \alpha-\frac{1}{\pi} \ln \frac{e^{\prime} \Sigma^{1}}{e+1}\right. \\
& \left.-\frac{\cos \alpha}{\pi}\left[2\left(e^{\prime}-1\right)^{1 / 2} \tanh ^{-1}\left(\frac{e^{\prime}-1}{e^{\prime}+1}\right)^{1 / 2}-e^{\prime} \ln \left(e^{\prime}-1\right)+2\left(e^{2}-1\right)^{1 / 2} \tanh ^{-1}\left(\frac{e-1}{e+1}\right)^{1 / 2}-e \ln (e+1)\right]\right\}
\end{aligned}
$$

Equations $(B-9)$ and $(B-13)$ are a pair of simultaneous equations for $e$ and $e^{\prime}$, given $c, t, h(n+I)$, and $a$. Once $e$ and $e^{\prime}$ are deter mined, lift and drag may be obtained from the momentum equation using Eq. (B-6) or by integrating the pressure over the plate. Performing either of these operations, and reducing the results to coefficient form,

$$
C_{L}=\frac{\pi \sin 2 \alpha}{\pi \sin \alpha+\frac{\left(a e^{\prime}-1\right) \ln \left[\left(e^{\prime}+1\right) /\left(e^{\prime}-1\right)\right]-(a e+1) \ln \left[(e+1) /\left(e^{\prime}-1\right)\right]}{\left(e^{2}-1\right)^{1 / 2}+\left(e^{\prime 2}-1\right)^{1 / 2}-e^{\prime}-e}}
$$

and

$$
C_{D}=C_{L} \tan \alpha
$$

When the fluid is infinite, $h, e$, and $e^{\prime \rightarrow \infty}$ and

$$
C_{L \infty}=\frac{\pi \sin 2 \alpha}{\pi \sin \alpha+4}
$$

Hence

$$
\frac{C_{L}}{C_{L \infty}}=\frac{C_{D}}{C_{D \infty \infty}}=\frac{h(n+1)}{c}(L / \pi+\sin \alpha)\left[1-\frac{\left(e^{2}-1\right)^{1 / 2}+\left(e^{2}-1\right)^{I / 2}}{e^{\prime}+e}\right]
$$

Equation (B-17) is plotted in Fig. B-2 for several angles of attack for the case $t / c=1 / 3$. Small changes in $t / c$ have negligible effect on the force coefficients. 

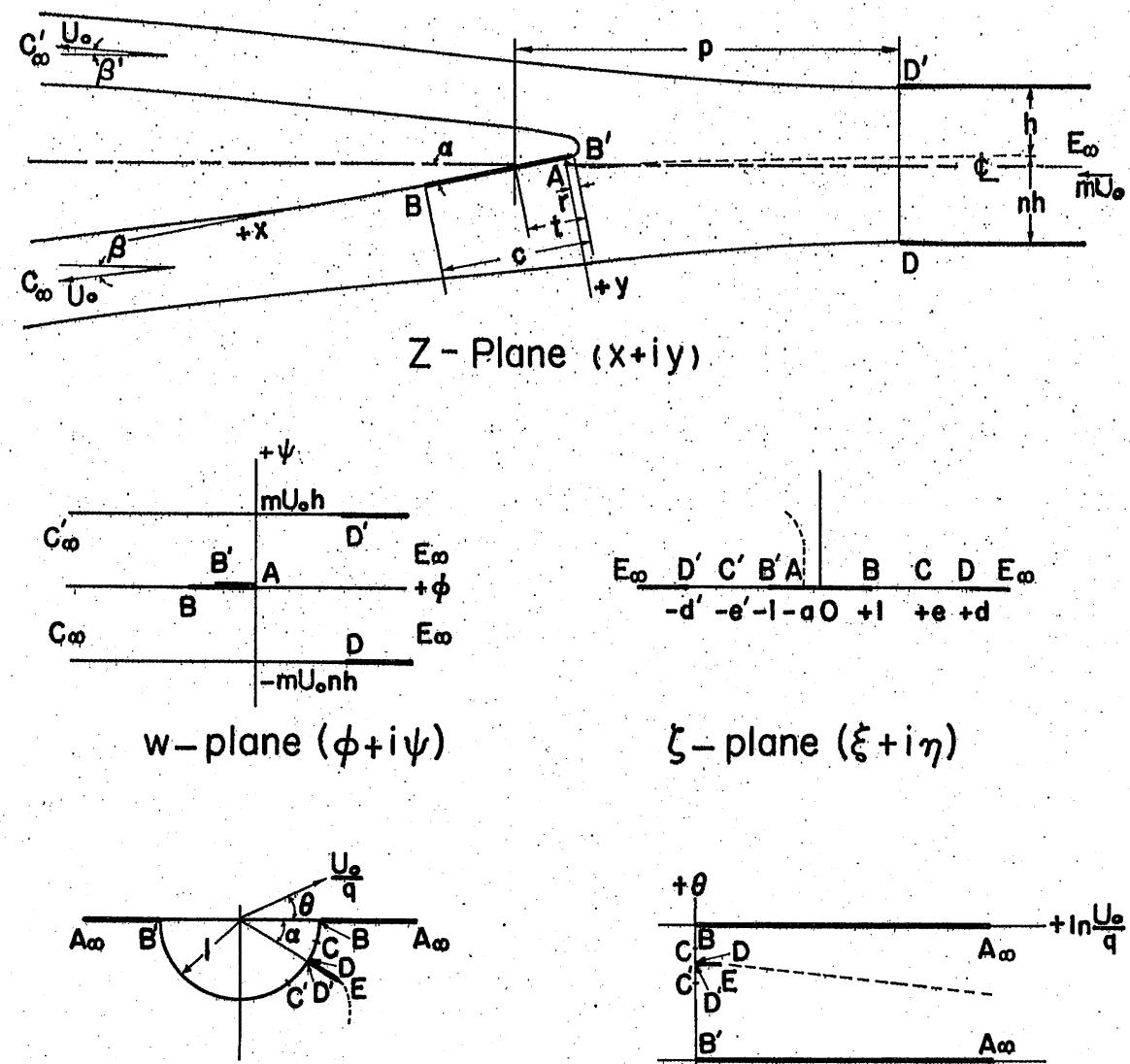

$$
\frac{U_{0}}{q} e^{i \theta}=-U_{0} \frac{d z}{d w} \text { plane }
$$

$$
\zeta \text {-plane }(\xi+i \eta)
$$

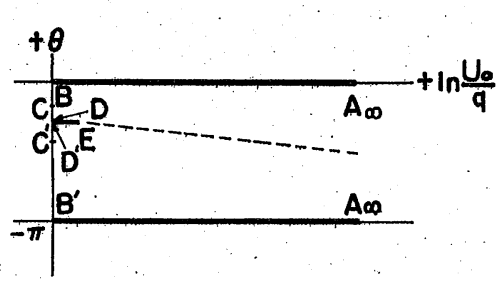

$$
Q=\operatorname{Ln} \frac{U_{0}}{q}+i \theta \text { plane }
$$

Fig. B-1 - Conformal Mapping Planes 


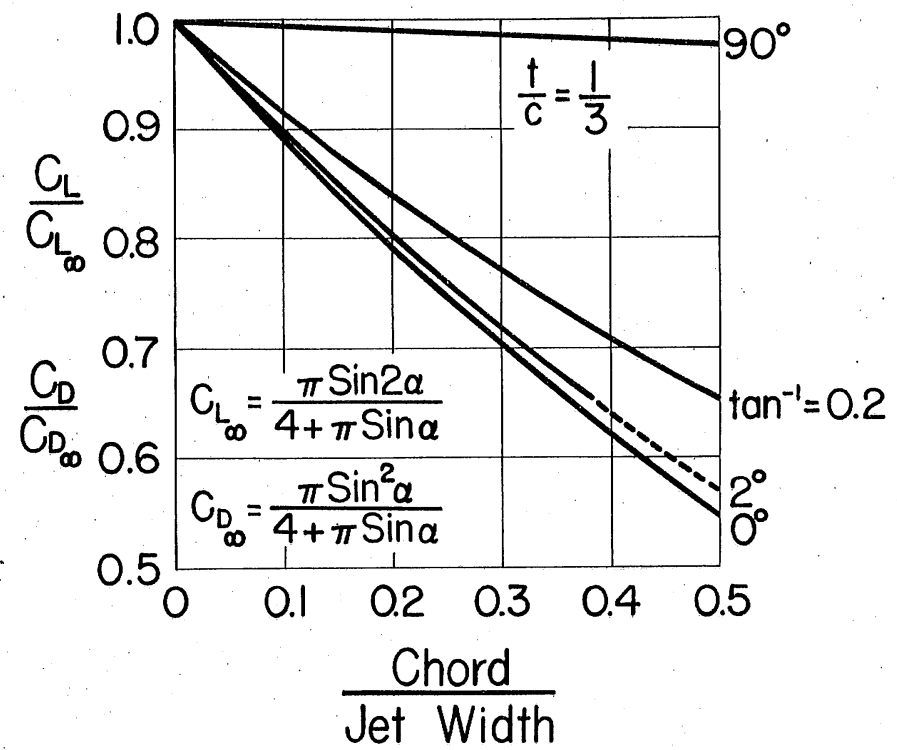

Fig. B-2 - Force Coefficients for Flat Plates in Free Jet at Zero Cavitation Number 
.

、 

DISTRIBUTION LIST FOR PROJECT REPORT NO。 59

of the St, Anthony Falls Hydraulic Laboratory

Copies

Organization

3. Chief of Naval Research, Department of the Navy, Washington 25, D. Co, Attn:

1 - Code 438

1 - Code 463

1 - Code 466

1 Commanding Officer, Office of Naval Research Branch Office, The John Crerar Library Building, 86 East Randolph Street, Chicago 1, Illinois.

1 Commanding Officer, Office of Naval Research Branch Office, 346 Broadway, New York 13, New York.

1 Commanding Officer, Office of Naval Research Branch Office, 1030 East Green Street, Pasadena 1, California.

1 Commanding Officer, Office of Naval Research Branch Office, 1000 Geary Street, San Francisco 9, California.

25 Commanding Officer, Office of Naval Research, Navy 100, Fleet Post Office, New York, New York, A.t.n: Mr. Mo Po Tulin.

6 Director, Naval Research Laboratory, Washington 25, D. C., Attn: Technical Information Office (Code 2000).

2. Chief, Bureau of Aeronautics, Department of the Navy, Washington 25, Do Co, Attn:

1 - Aero and Hydro Branch (Code $\mathrm{AD}-3$ )

1 - Research Division (Code RS)

2 Chief, Bureau of Ordnance, Department of the Navy, Washington 25, D. C., Attn:

1 - Assistant for Aero, Hydro, and Ballistics (Code Re03)

1 - Underwater Missile Branch (Code ReUI)

5 Chief, Bureau of Ships, Department of the Navy, Washington 25, D. C., Attn:

1 - Technical Assistant to Chief of Bureau (Code 106)

1 - Research and Development Division (Code 310)

1 - Technical Library (Code 312)

1 - Preliminary Design Branch (Code 420)

1 - Propellers and Shafting (Code 554)

5 Commanding Officer and Director, David Taylor Model Basin, Washington 7, D. C., Attn:

1 - Library Branch (Code 142)

1 - Téchnical Director for Hydromechanics Laboratory (Code 500)

1 - Contract Research Administrator (Code 513)

1 - Propeller Branch (Code 526)

I - Fluid Dynamics Branch (Code 591) 
I Commander, U. S. Naval Ordnance Test Station, China Lake, California, Attn: Library Division (Code 753)。

1 Officer-in-Charge, Pasadena Annex, U. S. Naval Ordnance Test Station, 3202 E. Foothill Boulevard, Pasadena, California, Attn: Iibrary Section (Code P80962).

1 Commanding Officer and Birector, U. S. Naval Engineexing Experiment Station, Annapolis, Maryland.

I' Commander, Naval Proving Ground, Dahlgren, Virginia, Attn: Technical Library Division (AAL).

1. Commander, $U_{0} S_{0}$ Naval Oxdnance Laboratory, White Oak, Maryland, Attn: Libraxy Division (Desk HL)。

I Commanding Officer, U. So Naval Underwater Ordnance Station, Newport, Rhode Island, Attn: Research Division.

1 Mr. $C_{0} R_{0}$ Dennison, Coordinator of Research, Maritime Administration, $441 \mathrm{G}$ Street, $\mathrm{N}_{0} \mathrm{~W}_{0}$, Washington $25, \mathrm{D}_{0} \mathrm{C}$ 。

3 National Bureau of Standards, Washington 25, D. C..9 Attn:

1 - Fluid Mechanics Section

1 - Dro $G_{0} \cdot B_{0}$. Schubauer

1 - Dro $\mathrm{G}_{0}$ H. Keulegan

I National Academy of Sciences, National Research Council, 2101 Constitution Avenue, $N_{0}$. Wo, Washington, $D_{0} C_{0}$

1 Superintendent, Uo So Naval Academy, Annapolis, Maryland, Attn: Librarian.

1 Superintendent, U. So Naval Postgraduate School, Monterey, California, Attn: Librarian.

1 Superintendent, U。 So Merchant Marine Academy, Kings Point, Long Island, New York, Attn: Captain L. S. McCready, Head, Department of Engineering.

1 Air Force Office of Scientific Research, Mechanics Division, WashIngton $25, D_{0} \mathrm{C}$ 。

1 Commanding Officer, Office of Ordnance Research, Box CM, Duke Station, Durham, North Carolina.

5 Director of Research, National Advisory Committee for Aeronautics, $1512 \mathrm{H}$ Street, $\mathrm{N} . \mathrm{W}_{0}$, Washington $25, \mathrm{D}$. C 。

1 Mr. Jo Bo Parkinson, Langley Aeronautical Laboratory, National Advisory Committee for Aeronauties, Langley Field, Virginia.

1 Director, Engineexing Sciences Division, National Science Foundation, $1520 \mathrm{H}$ Street, $\mathrm{N}_{0} \mathrm{~W}_{0}$, Washington, $\mathrm{D}_{0} \mathrm{C}_{0}$ 
5 Document Service Center, Armed Services Technical Information Agency, Arlington Hall Station, Arlington 12, Virginia.

1 Office of Technical Services, Department of Commerce, Washington 25 , D. C.

4 California Institute of Technology, Pasadena 4, California. Attn: 1 - Professor C. B. Millikan

I - Professor T. Y. Wu

1 - Professor A. Acosta

1 - Hydro. Laboratory

University of California, Berkeley 4, California, Attn:

1 - Department of Engineering

1 - Professor H. A. Schade

1 - Professor J. V. Wehausen

1 Director, Scripps Institution of Oceanography, University of California, La Jolla, California.

1 Director, Woods Hole Oceanographic Institute, Woods Hole, Massachusetts.

1 Professor M. Albertson, Department of Civil Engineering, Colorado State University, Fort Collins, Colorado.

2. Iowa Institute of Hydraulic Research, State University of Iowa, Iowa City, Iowa. Attn:

1 - Professor H. Rouse, Director

1 - Professor L. Landweber

2 Harvard University, Cambridge 38, Massachusetts, Attn:

1 - Professor G. Birkhoff (Department of Mathematics)

I - Professor G. F. Carrier (Division of Engineering and Applied Physics).

2. Massachusetts Institute of Technology, Cambridge 39, Massachusetts, Attn:

I - Professor L. Troost (Department of N.A. and M.E.)

I - Professor A. T. Ippen (Hydro. Laboratory)

3 University of Michigan, Ann Arbor, Michigan, Attn:

1 - Professor R. B. Couch (Department of N.A. and M.E.)

1 - Professor C.-S. Yih (Department of Engineering Mechanics)

1 - Professor V. Streeter (Department of Civil Engineering)

1 Director, St. Anthony Falls Hydraulic Laboratory, University of Minnesota, Minneapolis 14, Minnesota.

1 Director, Alden Hydraulic Laboratory, Worcester Polytechnic Institute, Worcester, Massachusetts.

1 Director, Ordnance Research Laboratory, Pennsylvania State University, University Park, Pennsylvania. 
1 Director, Institute of Mathematical Sciences, New York University, 25 WaverIy PIace, New York 3, New York.

1 Professor J. J. Foody, Engineering Department, New York State University Maritime College, Fort Schulyer, New York.

1 Technical Iibrary, Webb Institute of Naval Architecture, Crescent Beach Road, Glen Cove, Long Island, New York.

1 Professor W. R. Sears, Graduate School of Aeronautical Engineering, Cornell University, Ithaca, New York。

1 Professor S. Corrsin, Chairman, Mechanical Engineering Department, The Johns Hopkins University, Baltimore 18, Maryland.

1 Society of Naval Architects and Marine Engineers, 74 Trinity Place, New York 6, New York.

1. Engineering Societies Libraxy, 29 West 39th Street, New York 18, New York.

3 Stevens Institute of Technology, Experimental Towing Tank, 711 Hudson Street, Hoboken, New Jersey. Attn:

1 - Technical Director

1 - Dr. P. Kaplan

1 - Mr. D. Savitsky

1 Dr.J. Kotik, Technical Research Group, 17 Union Square West, New New York 3, New York.

I. Director, Institute for Fluid Mechanics and Applied Mathematics, University of Maryland, College Park, Maryland.

1.. Division of Applied Mathematics, Brown University, Providence 12, Rhode Island.

1 Hydrodynamies Iaboratory, National Research Council, Ottawa, Canada.

1 Professor I. Mo Milne-Thomson, Mathematical Research Center, 1118 W. Johnson Center, Madison 6, Wisconsin.

1 Dr. J. Mo Robertson, Department of Theoretical and Applied Mechanics, College of Engineering, University of Illinois, Urbana, Illinois.

2 Stanford University, Stanford, California, Attn:

1 - Professor J. K. Vennard (Civil Engineering Department)

1 - Applied Mathematics and Statistics Laboratory

I. Professor J. B. Herbich, Civil Engineering Department, Lehigh University, Bethlehem, Pennsylvania.

1 Dean J. S. MeNown, Department of Applied Mechanics, University of Kansas, Lawrence, Kansas. 
1 Professor A. G. Strandhagen, Department of Engineering Mechanics, University of Notre Dame, Notre Dame, Indiana.

2. Polytechnic Institute of Brooklyn, Department of Aeronautical Engineering and Applied Mechanics, 333 Jay Street, Brooklyn 1, New York, Attn:

1 - Professor A. Ferri

1 - Professor H. Reissner

1 Professor H. Cohen, Department of Mathematics, Rensselaer Polytechnic Institute, Troy, New York.

1 Professor D。 Gilbarg, Applied Mathematics and Statistics Laboratory, Stanford University, Stanford, Califormia.

1 Mr. Leo Geyer, Chief of Preliminary Design, Gruman Aircraft Engineering Corporation, Bethpage, Long Island, New York.

1 Mr. W. P. Carl, Jr., Dynamic Developments, Inc., Babylon, Iong Island, New York.

1 EDO Corporation, College Point, Long Island, New York.

1 Mr. H. E. Brooke, Hydrodynamics Laboratory, Convair, San Diego 12, California.

1 Miami Shipbuilding Corporation, 615 S. W. Second Avenue, Miami 36, Florida.

1. Baker Manufacturing Company, Evansville, Wisconsin.

1 Gibbs and Cax, Inc., 21 West Street, New York 16, New York. 


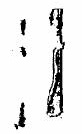

